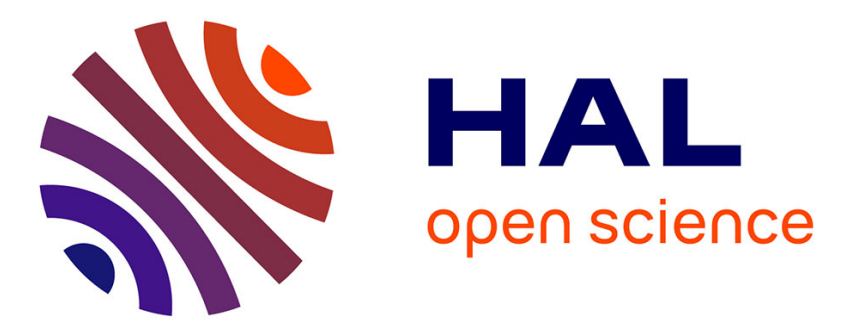

\title{
The Nexus between Labor Diversity and Firm Innovation
}

\author{
Pierpaolo Parrotta, Dario Pozzoli, Mariola Pytlikova
}

\section{To cite this version:}

Pierpaolo Parrotta, Dario Pozzoli, Mariola Pytlikova. The Nexus between Labor Diversity and Firm Innovation. Journal of Population Economics, 2014, 27(2), pp.303-364. 10.1007/s00148-013-0491-7 . hal-01513968

\section{HAL Id: hal-01513968 \\ https://hal.science/hal-01513968}

Submitted on 14 Jun 2018

HAL is a multi-disciplinary open access archive for the deposit and dissemination of scientific research documents, whether they are published or not. The documents may come from teaching and research institutions in France or abroad, or from public or private research centers.
L'archive ouverte pluridisciplinaire HAL, est destinée au dépôt et à la diffusion de documents scientifiques de niveau recherche, publiés ou non, émanant des établissements d'enseignement et de recherche français ou étrangers, des laboratoires publics ou privés. 


\title{
The Nexus between Labor Diversity and Firm's Innovation
}

\author{
Pierpaolo Parrotta, ${ }^{*}$ Dario Pozzoli ${ }^{\dagger}$ and Mariola Pytlikova ${ }^{\ddagger}$
}

\begin{abstract}
In this paper we investigate the nexus between firm labor diversity and innovation using data on patent applications filed by firms at the European Patent Office and a linked employer-employee database from Denmark. Exploiting the information retrieved from these comprehensive data sets and implementing proper instrumental variable strategies, we estimate the contribution of workers' diversity in cultural background, education and demographic characteristics to valuable firm's innovation activity. Specifically, we find evidence supporting the hypothesis that ethnic diversity may facilitate firms' patenting activity in several ways by: (a) increasing the propensity to (apply for a) patent, (b) increasing the overall number of patent applications and (c) by enlarging the breadth of patenting technological fields, conditional on patenting. Several robustness checks corroborate the main findings.
\end{abstract}

JEL Classification: J15, J16, J24, J61, J82, O32.

Keywords: Labor diversity, ethnic diversity, patenting activity, extensive and intensive margins.

\footnotetext{
*University of Lausanne, Quartier Dorigny, 1015 Lausanne, Switzerland. Email: pierpaolo.parrotta@unil.ch. Aarhus University; Aarhus, Denmark.

${ }^{\dagger}$ The Danish Institute for Regional Government Research (KORA), Købmagergade 22, 1150 Copenhagen, Denmark. Email: dapo@kora.dk. Aarhus University, Aarhus, Denmark. IZA, Bonn, Germany.

${ }^{\ddagger}$ The Danish Institute for Regional Government Research (KORA), Købmagergade 22, 1150 Copenhagen, Denmark. Email: mapy@kora.dk. CReAM, London, United Kingdom.
} 


\section{Introduction}

Many developed and developing countries have experienced several changes in the workforce composition which has led to an increased heterogeneity of the labor force in terms of age, gender, skills and ethnicity. This is partly the result of policies adopted to counteract the problem of population aging, anti-discrimination measures, immigration and the worldwide globalization process (Pedersen et al. 2008). From the demand side, we observe increasing diversity across many workplaces and we often hear about the importance of further internationalization and demographic diversification. The promotion of diversity is often perceived as a chance to improve learning and knowledge management capabilities and then enhance firm productivity (Parrotta et al. 2011). Besides, workforce diversity is believed to be an important source of innovation. For instance, in a relatively recent survey conducted by the European Commission, a large number of respondents identified innovation as a key benefit of having diversity policies and practices (European Commission 2005). If this is the case, firms could benefit from the growing diverse cultural backgrounds, demographic, and knowledge bases of the workforces. Moreover, since there is a widespread consensus that innovation is crucial for sustainable growth and economic development (as suggested in the new growth theories), understanding the link between workforce diversity and innovation seems to be essential for policy makers.

From a theoretical point of view, a paradox has been recognized: whereas a high degree of heterogeneity among workers can be a source of creativity and therefore foster innovation activity, it can also induce misunderstanding, conflicts and uncooperative behaviors within workplaces and in this way hinder innovation (Basset-Jones 2005). There is no general agreement on which effect prevails. Specifically, differences in skills, education and more broadly in knowledge among employees seem to be beneficial rather than detrimental (Watson et al. 1993, Drach-Zahavy and Somech 2001, Lazear 1999, Osborne 2000, Hong and Page 2001, Berliant and Fujita 2011). Ambiguity instead persists for diversity in ethnic and demographic characteristics of employees (Becker 1957, Williams and O'Reilly 1998, Zajac et al. 1991, Lazear 1999). 
Some empirical studies ${ }^{1}$ have explored the link between labor diversity and firm's innovation, and just a few of them have made use of comprehensive matched employer-employee dataset (Østergaard et al. 2011, Söllner 2010) or have properly addressed endogeneity issues related to the identification of the effects of workforce diversity of firm-level innovation outcomes (Ozgen et al. 2011b). Also our study investigates the nexus between labor diversity and innovation using a rich and register-based linked employer-employee data set from Denmark for the period 1995-2003. However we try to deal with several problems that previous literature studying the impact of workforce diversity on innovation has often not properly addressed. Most importantly, if firms are aware of the importance of labor diversity and leverage it to improve their performance, then the relationship under investigation is very likely to be affected by endogeneity. As an attempt to address these concerns, we implement an instrumental variable (IV) strategy à la Card (2001) based on measures of historical workforce diversity patterns at the commuting area level (where a firm is located) as instruments for the current firm labor diversity. In addition, we use an alternative instrument for the workplace ethnic diversity based on foreign population shares at the commuting areas predicted from a model of migration determinants. Furthermore, firms are characterized by a different propensity to innovate. Thus, there exist unobserved and observed firm-specific heterogeneity that should be taken into account to evaluate the effect of any labor diversity dimension on firm's innovation outcome. As we do not have sufficient data variation to undertake panel estimations, we use pre-sample information to proxy for unobservable permanent firm characteristics (Blundell et al. 1995). Finally, we control for the potential role of the external knowledge in favoring firms' patenting activity and compute knowledge spillovers indicators based on geographical and technological distances between firms.

Regarding measures of innovation, we follow previous literature and make use of information on patents to proxy for innovation (Griliches 1990, Bloom and Van Reenen 2002). Specifically, we use the following three measures: (1) firm's propensity to apply for a patent, (2) the number of patent applications introduced each year and (3) firm's propensity to apply in more than one technological area, conditional on applying for a patent. We investigate

\footnotetext{
${ }^{1}$ See next section for a brief overview of the literature.
} 
the effect of labor diversity on firm innovation by looking at three dimensions of employee diversity: cultural background, education and demographics. The comprehensive data allows us to dig deeper into the mechanisms by which diverse workforces may affect innovation. In particular, we test whether (a) the beneficial effects of diverse problem-solving abilities and creativity would materialize more in terms of innovation for white-collar occupations compared to blue-collar occupations, (b) communication costs associated with ethnic diversity may increase after subtracting out foreigners who are likely to speak Danish or English.

Implementing alternative estimation techniques, we find evidence of the key role of ethnic diversity in promoting firm's innovation as measured by the number of patent applications, the probability to apply for a patent or to patent in more than one technological field, conditional on patenting. The contribution of ethnic diversity to start patenting and to the number of firms' patent applications is economically meaningful. Furthermore, the effect of ethnic diversity on extensive margins is very large: conditional on patent application, a standard deviation increase in ethnic diversity almost duplicates the probability to patent in different technological fields, according to the most conservative estimates. Effects of diversity in education and demographics turn out to be mostly insignificant when either the full set of controls is included or endogenity is taken care of. These results support the hypothesis that ethnically diverse workers tend to have a wider pool of different experiences, knowledge bases and heuristics boosting their problem-solving capacities and creativity, which in turn facilitate innovations.

The structure of the paper is as follows: section 2 reviews related literature and derives hypotheses, section 3 briefly describes the data, section 4 provides details on the empirical strategy, section 5 explains all the results of our empirical analyses and section 6 offers some concluding remarks. 


\section{Literature background and hypotheses development}

One of the most relevant theoretical contribution, describing the role of workforce diversity in terms of firm's level outcomes, is by Lazear (1999). His model predicts positive effects of educational/skill diversity on firm performance as long as workers' information sets are not overlapping but relevant to one another. Thus, being educational diversity a measure of skill complementarity and knowledge spillovers, it is very likely to have a positive influence on firm's innovation activity. Furthermore, referring to the role of high skilled workers, Berliant and Fujita (2011) propose a model in which the composition of the research workforce in terms of knowledge heterogeneity positively affects the production of new knowledge as it accelerates the generation of new ideas through individual-level production complementarities.

Conversely, it is less straightforward to predict the directions of the effects of diversity in ethnicity and demographic characteristics, as such dimensions may bring high communication costs and low social ties and trust, which may hinder knowledge spillovers and exchange among diverse employees (Lazear 1999). Specifically, ethnic diversity may create communication barriers, reduce the workforce cohesion and prevent cooperative participation in research activities, bringing high costs of "cross-cultural dealing" (Williams and O'Reilly 1998, Zajac et al. 1991, Lazear 1999). Indeed, demographic heterogeneity among workers may create communication frictions if workers are prejudiced, and therefore bring some cost connected to these frictions (Becker 1957). On the other hand, diversity in both ethnic and demographic dimension may also bring substantial benefits in terms of firm innovation outcomes. Employees of different cultural backgrounds may provide diverse perspectives, valuable ideas, problem-solving abilities, and in this way facilitate the achievement of optimal creative solutions and therefore stimulate innovations (Watson et al. 1993, Drach-Zahavy and Somech 2001, Hong and Page 2004; Berliant and Fujita 2011). Given that cultural heterogeneity is often a good proxy for cognitive diversity, ethnically diversified workforces may exploit a larger pool of knowledge. Hong and Page (2001) present a model of agents of bounded abilities and analyze their individual and collective performance. Agents are 
heterogeneous as they differ in their perspectives (internal representations of the problems) and heuristics (algorithms they use to generate solutions). The authors find that "diversity in either perspectives or heuristics proves sufficient for a collection of agents to allocate optimal solutions to difficult problems". Moreover, employees of different ethnic backgrounds may stimulate firm to improve or develop new products sold abroad as they also possess knowledge about global markets and customers' tastes (Osborne 2000, Kerr and Lincoln 2010, Hatzigeorgiou and Lodefalk 2012, Hiller 2013). Concerning the positive influence of demographic diversity on firm performance, it seems plausible to assume for instance that age heterogeneity may facilitate innovation because there are complementarities between the human capital of younger and older workers: younger employees have knowledge of new technologies and IT and older employees have a better understanding and experience with the intra-firm structures and the operating process (Lazear 1998).

The empirical literature exploring the relationship between labor diversity and firm's innovation consists of (i) business case studies that often look at work-team compositions (Horwitz and Horwitz 2007, and Harrison and Klein 2007), (ii) works focusing on diversity in top management teams only (Bantel and Jackson 1989, Knight et al. 1999, Pitcher and Smith 2001), (iii) analyses linking workforce heterogeneity - typically ethnic diversity - to innovation using aggregate regional or industry data (Kelley and Helper 1999, Feldman and Audretsch 1999, Anderson et al. 2005, Niebuhr 2010, Kerr and Lincoln 2010, Ozgen et al. 2011a, Nathan 2012), (iv) a few firm level studies using linked employer-employee data (Østergaard et. al. 2011, Söllner 2010, Ozgen et al. 2011b).

The limited number of empirical studies at the firm level may be imputed to differences in research aims and approaches, but also to the lack of more comprehensive employer-employee data, which provide a notable amount of information on the labor force composition at the firm level. To the best of our knowledge, the evidence using more comprehensive data is rather scarce. Only three recent studies analyze the relationship between labor heterogeneity and firm innovation outcomes, using linked employer-employee data (LEED). The first work is Østergaard et. al. (2011), which merges the Danish LEED for the year 2002 with a survey that refers to the period 2003-2005 (Danish Innovation System: Comparative analyses, 
strength and bottlenecks, DISKO) and analyzes a cross-section of 1,648 firms. This study finds evidence of (a) positive effect of diversity in education and gender, (b) no significant effects of ethnic diversity and (c) negative effects of age diversity on firm's innovation. The second study by Söllner (2010) evaluates how occupational diversity, considered as a proxy of human capital heterogeneity, is linked to the firm's likelihood to introduce a product innovation. Controlling for age and tenure diversity among other covariates, Söllner (2010) finds that occupational diversity is positively related to the propensity to innovate. However, none of these studies addresses endogeneity issues related to the identification of the effects of diversity on firm innovation, which we take into account in the present article. Ozgen et al. (2011b) is the third study. It investigates the impact cultural diversity on innovation by matching information from the Dutch Labor Force Survey to Community Innovation Survey 3.5. Their final sample consists of 4,638 firms over the period 2000-2002. Using the number of foreign restaurants and the historical presence of immigrant communities per municipality as instruments for the immigrant settlement, they find that whereas firms with large shares of foreigners are less innovative, a more diverse workforce positively affects firm innovativeness. Although Ozgen et al. (2011b) propose an interesting IV strategy, they end up using a relatively small sample of firms to evaluate the impact of cultural diversity on firm propensity to introduce an innovation. Further, they do neither look at other labor diversity dimensions nor take extensively into account firm unobserved heterogeneity as we do in the present study.

Based on the existing theoretical literature, we derive our hypotheses for the effects of labor diversity on firm's innovation activity. First, we expect to find a positive contribution of educational diversity to firm's innovation, as soon as workers' information sets are not overlapping but relevant to one another. Second, we don't have any clear prior on the directions of the effects, as benefits from diversity in these dimensions may be compensated by potential costs associated with communication and distrust among employees. Finally, given that workforce diversity ought to be translated into larger spectrum of perspectives, heuristics and knowledge (Hong and Page 2001, Berliant and Fujita 2011), we might expect that the workforce diversity may affect not only the scale, but also the scope of innovation. 
In other words, we expect workforce diversity to not only affect the probability to innovate and the extent of firm's innovation activity, but also the variety of technological fields, in which firm innovates.

As the comprehensiveness of our data allows us to dig deeper into the mechanisms by which diverse workforces may affect innovation, we test two further hypotheses. Firstly, we test the creativity hypothesis proposed in the theoretical frameworks by Hong and Page (2001) and Berliant and Fujita (2011). Specifically, we expect that the beneficial effects of diverse problem-solving abilities and creativity originating from knowledge complementarities would materialize more in terms of innovation for white-collar occupations (high skilled employees) compared to blue-collar occupations (low skilled employees). Secondly, we exclude certain groups of foreigners from the calculation of ethnic diversity measures to test whether the costs of "cross-cultural dealing" play a role. In particular, we expect that communication costs associated with ethnic diversity may increase after subtracting out foreigners who are likely to speak Danish or English.

\section{Data}

\subsection{Data sources}

The data set we use for our analysis is obtained by merging three different data sources from Denmark. The first one is the 'Integrated Database for Labor Market Research' (IDA), which is a register-based LEED managed by Statistics Denmark, a Danish governmental institute in charge for creating statistics on the Danish society and economy. IDA contains a broad set of information on individuals and firms for years 1980-2006. In particular, we are interested in gender, age, nationality, education, occupation, tenure, place of work, whether a company is (partially or totally) foreign-owned and a multi-establishment firm. The second data source is a register of firms' business accounts (REGNSKAB) that provides information on a number of financial items, which we need in order to construct values of firms' capital stock, information on whether a firm is an exporter and the 3-digit industry, 
in which the firm operates. This database is also maintained by the Statistics Denmark and reports data for the period $1995-2005 .^{2}$ In REGNSKAB it is possible to identify partially and totally imputed values, which we exclude from our final data set in order to avoid any bias in the estimates. The last data source is a collection of patent applications sent to the European Patent Office (EPO) by Danish firms. ${ }^{3}$ It covers a period of 26 years (19782003) and allows us to account for 2,822 applicants, corresponding to 2,244 unique firms. ${ }^{4}$ Unfortunately the patent data, that has been provided to us by the Center for Economic and Business Research and that has been merged to the Danish register data, only cover the number of patent applications and grants, together with a classification of patents in technological areas. Hence our data does not include any variable that has been used by the main literature in this field to proxy for the quality and traits of innovations (Trajtenberg 1990, Lanjouw et al. 1998, Hall et al. 2005). For instance, both the forward citation weights of patents and measures of originality/generality of inventions are missing. These data limits prevent us from assessing to what extent workforce diversity impacts on the quality and traits of innovations. Furthermore, it is important to underline that patents as a measure of firm innovation, like any other innovation indicators, present both advantages and disadvantages (Archibugi and Planta 1996). On the positive side, patent applications (i) are a direct outcome of the innovation process, (ii) need some efforts to be documented, (iii) are broken down by technical fields (IPC) informing this way on the directions of performed innovation activities. On the other side though not all inventions are necessarily linked to patent applications or technically patentable and firms may present different propensity to apply for a patent. All in all, though with some important limitations, we believe that patent applications may represent a plausible and suitable proxy for firm's innovation activity, being somehow a rather conservative and objective measure of innovation.

\footnotetext{
${ }^{2}$ Part of the statistics in REGNSKAB refers to selected firms for direct surveying: all firms with more than 50 employees or profits higher than a given threshold. The rest is recorded in accordance with a stratified sample strategy. The surveyed firms can choose whether to submit their annual accounts and other specifications or to fill out a questionnaire. In order to facilitate responding, questions are formulated in the same way as required in the Danish annual accounts legislation.

${ }^{3}$ The access to these data has been made possible thanks to the Center for Economic and Business Research (CEBR), an independent research center affiliated with the Copenhagen Business School (CBS).

${ }^{4}$ More details concerning the construction and composition of the data set can be found in Kaiser, Kongsted and Rønde (2008).
} 
Therefore the focus of this study is on the following firm innovation outcomes: i) the firm's propensity to apply for a patent, ii) the number of patent applications for each year and iii) the firm's propensity to apply in more than one technological area, conditional on patenting. We disregard industries ${ }^{5}$ with no patenting firms during the period covered in our empirical analysis. We also exclude enterprises with less than 10 employees from our sample to allow all investigated firms to reach (potentially) the highest degree of (ethnic) diversity at least when an aggregate specification is used, as outlined in the next section. Finally we leave out firms that were founded during the estimation period (1995-2003), given that we use a "pre-sample" estimator that requires information on firms' patenting behavior prior to 1995 . Thus, our final data set contains information on approximately 12,000 firms per year over a period of 9 years (1995-2003).

\subsection{Diversity measures}

The workforce diversity (heterogeneity) measures used in this article are computed at the workplace level and then aggregated at the firm level and are based on the Herfindahl index. The latter combines two important dimensions of diversity: the "richness", which refers to the number of defined categories within a firm, and the "evenness", which informs on how equally populated such categories are. Specifically, our diversity measures represent weighted averages of Herfindahl indexes computed at the workplace level:

$$
\text { Index_ } h_{i t}=\sum_{w=1}^{W} \frac{N_{w}}{N_{i}}\left(1-\sum_{s=1}^{S} p_{w s t}^{2}\right)
$$

where Index_ $h_{i t}$ is the diversity index of firm $i$ at time $t$ for the dimension $h, W$ is the total number of workplaces ( $w$ refers to a given workplace) constituting the firm, and therefore $N_{w}$ and $N_{i}$ denote the total number of workers at the workplace and firm levels, respectively. Thus, the ratio between the last two variables corresponds to the weighting function, while $p_{w s t}$ is the proportion of the workplace's employees falling into each category $s$ at time $t$, with

\footnotetext{
${ }^{5}$ Agriculture, fishing and quarrying; electricity, gas and water supply; sale and repair of motor vehicles; hotels and restaurants; transports; and public services.
} 
$s=1,2, \ldots, S$. The diversity index has a minimum value, which takes value on zero if there is only one category represented within the workplace, and a maximum value equal to $\left(1-\frac{1}{S}\right)$ if all categories are equally represented. This index can be interpreted as the probability that two randomly drawn individuals in a workplace belong to different groups. However, the Herfindahl index presents some limitations when it comes to high or low levels of diversity (Dawson 2012). For such a reason, we perform some sensitivity analysis by measuring diversity using two alternative approaches (the Shannon-Weaver and the richness indexes) which are proven to be more robust at the extreme tails of the distribution of diversity but may present some flaws for intermediate values of diversity (Jost 2006, Dawson 2012).

As we distinguish between cultural (ethnic), educational (skill) and demographic diversity, a separate measure is computed along each of the three cited dimensions. Diversity in cultural background is associated with foreign employees' country of origin and is built by using the following eight categories, from which native Danes are excluded: North America and Oceania, Central and South America, Africa, Western and Southern Europe, Formerly Communist Countries, East Asia, Other Asia, Muslim Countries. ${ }^{6}$ Diversity in skill/education is based on six categories. In particular, tertiary education (PhD, Master and Bachelor) is divided into the following four groups: engineering, humanities, natural sciences and social sciences. The other two categories are represented by secondary and compulsory education. Eight categories instead refer to the demographic diversity, which is computed by combining gender and four age dichotomous indicators associated with quartiles of the overall age distribution.

Given that the overall categorization might be somehow arbitrary, we decide to use a more disaggregate one, too. The alternative cultural background diversity is based on linguistic classification. ${ }^{7}$ Specifically, we group foreign employees together by family of languages, to which the language spoken in their home country belongs. ${ }^{8}$ Using the third linguistic tree level language classification drawn from Ethnologue, we end up having 40 lin-

\footnotetext{
${ }^{6}$ See Appendix 1 for more details about the countries belonging to each ethnic category.

${ }^{7}$ Previous literature argues that linguistic distance serves also as a proxy for cultural distance (Guiso et al. 2009; Adsera and Pytlikova 2012).

${ }^{8}$ Specifically, we use the official language spoken by majority in a given country of origin to link the country into groups by family of languages.
} 
guistic groups. ${ }^{9}$ Further, our disaggregated diversity indexes in education and demographics are based on eight and ten categories, respectively. Differently from the former classification, the secondary education is split into 3 sub-groups: general high school, business high school and vocational education. Demographic diversity is computed by combining gender and five age dichotomous indicators associated with quintiles of the overall age distribution.

\subsection{Descriptive statistics}

Table 1 reports some descriptive statistics of the variables used in our empirical analysis. Besides showing means and standard deviations for the full sample of firms, we also split the firm population into two groups based on whether a firm applied for at least one patent (patenting firm) or did not, and we show the descriptive statistics for patenting and non-patenting firms. As we can observe from the Table 1, there are remarkable differences between patenting and non-patenting firms with respect to firms' workforce composition. Not surprisingly, patenting firms are characterized by larger shares of highly educated employees, professionals and technicians. Interestingly, patenting firms also record a higher share of female and foreign employees. Workers in these knowledge-based firms are slightly older on average terms: presumably the share of young employees is lower because patenting firms hire a wider proportion of well trained and experienced people. As a matter of fact long tenure profiles are more common within patenting firms' environment. Regarding the workforce diversity variables, central for the main hypotheses in this paper, there is a number of interesting facts arising from the Table 1. First, it is obvious that patenting firms in Denmark have more diverse workforces. In particular there is a clear difference between patenting and non-patenting firms with respect to the ethnic heterogeneity, which is more than 3 times larger on average in patenting firms. Patenting firms have also larger

\footnotetext{
${ }^{9}$ The linguistic classification is more detailed than the grouping by nationality categories. Specifically, we group countries (their major official language spoken by the majority in a particular country) by the third linguistic tree level, e.g. Germanic West vs. Germanic North vs. Romance languages. The information on languages is drawn from the encyclopedia of languages "Ethnologue: Languages of the World", see the Appendix section for more details about the list of countries and the linguistic groups included. Furthermore, we adjust the index to take account of the firm size. Specifically, we standardize the index for a maximum value equal to $\left(1-\frac{1}{N}\right)$ when the total number of employees $(N)$ is lower than the number of linguistic groups $(S)$.
} 
educational and demographic diversity compared to non-patenting firms.

Further, patenting firms are characterized by notably higher values of capital and labor inputs: the average capital stock is about 9.7 times the value of the non-patenting firms. Patenting firms are also more likely to be multi-establishment companies and markedly (82 percent) more export-oriented. Regarding the foreign owership status, in general we can observe that the foreign capital penetration is quite low among firms in Denmark, and there is no difference with respect to foreign ownership status between patenting and nonpatenting firms.

For the purposes of our analyses it appears relevant to take into account the role of external sources of knowledge since they may facilitate firms' innovation activity. Following the approaches suggested by Audretsch and Feldman (1996) and Adams and Jaffe (1996), we construct two indexes of knowledge spillovers. These are weighted sums of firms' codified knowledge proxied by the discounted stock of patent applications. ${ }^{10}$ The weighting function for the first index refers to the geographical distance between pairs of workplaces' municipalities and is computed by using the firms' latitude and longitude coordinates (the address of their headquarters). The second index is instead based on the technological proximity between pairs of workplaces. Appendix 2 provides a detailed description about how both external knowledge indexes are calculated. Looking at these measures of knowledge spillovers, see Table 1, we find no evidence of diffused clustering behavior or huge differences in technological distance between the two groups of firms.

Overall, the presented descriptives raise a reasonable interest in evaluating the "nexus" between workforce diversity in ethnicity, education and demographics and firms' patenting behavior, which is something we are going to investigate in depth in the next sections.

\section{Econometric methods}

\subsection{Propensity to innovate}

To investigate the effect of labor diversity on firm's propensity to innovate, we employ a

\footnotetext{
${ }^{10}$ Section 4.3 describes how the discounted stock of patent applications is calculated.
} 
standard binomial regression technique. Specifically, we estimate the following probit model:

$$
\begin{aligned}
& \qquad\left\{\begin{array}{c}
p_{i t}=1 \quad \text { if } p_{i t}^{*}>0 \\
p_{i t}=0 \text { otherwise }
\end{array}\right. \\
& \text { with } p_{i t}^{*}=\gamma_{c} \text { Index_ethnic } c_{i t}+\gamma_{e} \text { Index_eduit }+\gamma_{d} \text { Index_demo } o_{i t}+x_{i t}^{\prime} \beta+v_{i t}
\end{aligned}
$$

where $p_{i t}^{*}$ denotes the unobservable variable inducing firm $i$ to apply at least once for a patent at time $t ; p_{i t}$ indicates whether firm $i$ concretely has applied at time $t$; the first three terms at the right-hand side are diversity in ethnic background, education/skills and demographics respectively and $v_{i t}$ is the error term. The vector $x_{i t}^{\prime}$ includes an extensive set of observable characteristics that might affect firms' innovation outcomes. More specifically, we include detailed workforce composition characteristics such as shares of foreigners coming from a given group of countries under the aggregate diversity specification (e.g. shares of foreigners from North America and Oceania, Central and South America, Africa, Western and Southern Europe, Formerly Communist Countries, East Asia, Other Asia, and Muslim Countries), shares of males, of workers with either tertiary or secondary education, shares of differently aged workers belonging to the employees' age distribution quartiles and shares of workers for each occupation, according to the first digit classification code of occupation. ${ }^{11}$ We also control for the average firm tenure, whether the firm is an exporter, a foreign ownership dummy, a multi-establishment dummy and for possible knowledge spillover effects, by including two external knowledge indexes, as described in the previous section. Whereas the inclusion of spillover measures and foreign ownership status captures effects related to external knowledge production, controls on the workforce composition allow estimating the

\footnotetext{
${ }^{11}$ The Ministerial Order on the Statistics Denmark Act requires every employer in Denmark to report annually an occupational classification code for each of its full-time employees, following the DISCO. The DISCO is the Danish version of the ILO's ISCO (International Standard Classification of Occupations). Normally the DISCO code reporting to Statistics Denmark takes place directly through the company's electronic salary systems. Over the sample period, the DISCO codes have been updated regularly, with some codes being eliminated and some new codes being created. Of obvious concern is therefore the possibility of spurious changes in the DISCO codes assigned to workers who experience no real change in their occupations.We believe, however, that our analysis is largely free from such spurious changes in the DISCO codes, as we base our main analysis on one-digit classification. As shown in Frederiksen and Kato (2011), over the 1992-2002 period, reassuringly at the one-digit level, there was no new code added.
} 
effect of diversity, holding the shares of different worker types constant. The correlation between our diversity measures and the shares of each worker type in terms of ethnicity, education, age and gender in the data turns out to be rather modest ${ }^{12}$, which allows us to control for both variables at the same time and, thus, to separate mix and size effects of the workforce characteristics. Furthermore we think that the inclusion of such shares partly control for the fact that different group of foreign labour may have different qualities. We finally include a set of regional, year, industry and year times industry dummies in order to capture any business cycle influences, regional- or industry-specific effects.

\subsection{Identification}

If firms aim at labor diversity to improve their innovation performances, then the relationship under investigation is very likely to be affected by endogeneity. To address the potential endogeneity issues, we follow an instrumental variable (IV) strategy in order to obtain a causal effect of workforce diversity on firm innovation activities. More specifically, we instrument our diversity variables with indexes of workforce diversity in cultural background, skills and demographic characteristics, computed at the commuting area, ${ }^{13}$ where the firm is located. ${ }^{14}$ Given that the current geographical location of firms may not be random, we predict the current composition of the labor supply at the commuting area level by using its historical composition and the current population stocks (Card 2001). See also Card and Di Nardo (2000), Dustmann et al. (2005), Cortes (2008), Foley and Kerr (2012) for similarly

\footnotetext{
${ }^{12}$ In the aggregate specification, for example, the correlations between ethnic (demographic) diversity and the shares of workers from each ethnic (demographic) group are always below 0.30. The correlations between educational diversity and the shares of workers with either tertiary or secondary education are below 0.20 .

${ }^{13}$ The so-called functional economic regions or commuting areas are identified using a specific algorithm based on the following two criteria: firstly, a group of municipalities constitute a commuting area if the interaction within the group of municipalities is high compared to the interaction with other areas; secondly, at least one municipality in the area must be a center, i.e. a certain share of the employees living in the municipality must work in the municipality, too (Andersen 2000). In total 104 commuting areas are identified.

${ }^{14}$ Unfortunately in our dataset it is not possible to observe in which area each establishment of a multiestablishment firm is located. For multi-establishments firms, the information about the location is only provided at the headquarter level. However, we do not think this represents a serious problem as multiestablishments firms constitute only $11 \%$ of our sample. It is also important to note that most of firms included in our estimation sample remain in the same commuting area over the estimation period (19952003).
} 
computed instruments. Pre-existing workforce diversity at the commuting area level is unlikely to be correlated with a current firm's innovation, if measured with a sufficient time lag. In particular we use workforce composition at the commuting areas from year $1990 .{ }^{15}$ In this approach, for example, the predicted share of immigrants from country $c$ and living in a commuting area $l$ at time $t, \hat{m}_{c l t}$, is computed using the early 90 's stock of immigrants from country $c$ living in $l$ and its current population of immigrants:

$$
\hat{m}_{c l t}=\frac{\text { stock }_{c l 1990}}{\sum_{c=1}^{C} s_{\text {tock }} \text { clt }}
$$

We believe that diversity at the commuting area level presents a suitable supply driven instrument for workplace level diversity because commuting areas in Denmark (except for the area around Copenhagen) are typically relatively small and therefore firms very likely recruit workers from a given local supply of labor, which is characterized by a certain degree of heterogeneity. This argument is further reinforced by the role of networks in the employment process (Montgomery 1991, Munshi 2003). Thus firms placed in areas with high labor diversity are also more likely to employ a more diverse workforce. It is important to emphasize that although the commuting areas are not closed economies, in the sense that workers are free to move in and out, there is a clear evidence of low residential mobility among danes, no matter their educational level (Deding et al. 2009), which seems to support the properness of our IV strategy. We may be though not able to apply the same argument to high-skilled immigrants, who may be more mobile than the danes themselves. However previous studies have shown that immigrants have generally a tendency to settle down

\footnotetext{
${ }^{15}$ We chose year 1990 as a historical base for our predictions because we believe that the lag of 5 - 13 years should be a sufficient lag for the purposes of our IV construction. In addition, the development in immigration to Denmark also supports the choice. The eighties and nineties were characterized by rather restrictive immigration policy with respect to economic migrants from countries outside the European Union (EU), which made it rather difficult for firms in Denmark to hire applicants from the international pool of applicants (due to consequences of the Oil Crisis). Immigration to Denmark from those countries during the eighties til mid-nineties was rather characterized by immigration on the basis of humanitarian reasons and family-reunion. However, since then Denmark has further tightened its immigration policy (even laws concerning family reunification and asylum). In particular since the 2001 election, in which the right-wing Danish People's Party (DF) with its anti-immigration agenda acquired a significant political power, the immigration policy in Denmark became one of the strictest in the world. For firms it meant almost no possibilities to hire international workers from countries outside the EU, which has often been criticized by the Confederation of Danish Industry (DI). Given those historical developments, we decided to use shares of immigrants from 1990 as a base for our predictions.
} 
in areas where there are pre-existing migrants' networks and the presence of individuals with the same cultural and linguistic background as themselves (Damm 2009, Pedersen at al. 2008). ${ }^{16}$ We can then assume that pre-existing (from 5 to 13 years earlier) immigrant concentrations are unlikely to be correlated with current firm innovation. However, even though our instrument is based on the historical composition of the local labor supply, it may still be the case that our identification strategy is invalidated by the fact that firms choose locations that are rich in local innovation potential and therefore with a higher degree of diversity. Nonetheless previous studies on firm localization (Krugman 1991, Audretsch and Feldman 1996, Adams and Jaffe 1996, Alcacer and Chung 2010, Delgado et al. 2010) have shown that the location choices are mainly driven by the access to local innovation potential and knowledge spillovers and also by the size of the local demand, the proximity to customers and suppliers and the quality of local physical infrastructure. We believe that our measures of firms' knowledge spillovers, described in the previous section, should be able to partly address the potential endogeneity of firm location decisions in terms of knowledge spillovers. We use the described IV strategy for analyses of all three dimensions of innovation: propensity to innovate, intensive and extensive margins.

As a part of our robustness analyses, we also use an alternative instrument for ethnic diversity, in which our ethnic diversity levels at commuting areas are computed on the basis of the shares of foreign population predicted by an empirical model of determinants of migration. Specifically we run the following empirical specification, which is based on time variant push and pull factors, and costs of migration (Pedersen et al. 2008, Ortega and Peri 2009):

$$
m_{c l t}=\alpha+\theta_{t}+\left(\gamma_{l} * \theta_{t}\right)+\left(\sigma_{c} * \theta_{t}\right)+\lambda_{c l}+\epsilon
$$

\footnotetext{
${ }^{16}$ In the case of Denmark, there was also a special dispersal policy implemented for refugees between years 1986 and 1998 by the Danish authorities. The dispersal policy implied that new refugees were randomly distributed across locations in Denmark, see e.g. Damm (2009). This fact as well supports the validity of our instrument because the refugees, as a part of international migrants to Denmark, were not driven by the firm innovation outcomes when settling, but by those dispersal policies or by the migrant networks. In addition, the inflows of economic migrants are driven by push and pull factors of destination and origin countries, costs of migration and other bilateral relationships between the origins and destinations (Pedersen et al. 2008, Ortega and Peri 2009). We believe that those migration determinants are unlikely to be correlated with a firm's innovation outcomes.
} 
where $m_{c l t}$ is a share of foreigners from source country $c$ and living in a commuting area $l$ at time $t, \theta_{t}$ are year dummies, $\gamma_{l}$ and $\sigma_{c}$ are country of origin and commuting areas fixed effects, respectively, and $\lambda_{c l}$ are time invariant pair of country and commuting areas fixed effects, which represent controls for costs of migration and other bilateral historical relationship between the country of origin and commuting areas. We then predict the share of immigrants from country $c$ and living in a commuting area $l$ at time $t, \hat{m}_{c l t}$, based on the obtained coefficients from the empirical model of determinants of migration. Further, we use those predicted shares to compute an ethnic diversity index at the commuting area level and use it as an instrument for the workplace ethnic diversity. We believe that the determinants of migration are likely to be orthogonal with respect to innovation outcomes at the workplace levels. In this robustness check, diversity in the other two dimensions, i.e. educational and demographic, is instrumented as in the main analysis, i.e. by using the historical composition and the current population stocks of the labor supply at the commuting area level.

\subsection{Intensive margins}

Our point of departure for the analysis of the intensive margins, is the patent production function. Following a standard procedure within the literature (Blundell et al. 1995, Kaiser et al. 2008), we assume a Cobb-Douglas functional form. Moreover, as our dependent variable is the number of patents, which is by definition restricted to non-negative integers, the econometric strategy used to analyze the relationship between intensive margins of patenting activity and labor diversity is grounded on the family of count models. As a starting point we assume that the data generating process follows a Poisson distribution. If the random variable $Y_{i t}$, in our case number of patent applications filed by firm $i$ at time $t$, is Poisson distributed, then the probability that exactly $y$ applications are observed is as follows

$$
P\left(Y_{i t}=y \mid \lambda_{i t}\right)=\frac{e^{-\lambda_{i t}} \lambda^{y}}{y !}
$$


Covariates can be introduced by specifying the individual (firm) mean as

$$
\lambda_{i t}=\exp \left(\beta_{c} \text { Index_ethnic }_{i t}+\beta_{e} \text { Index_edu }_{i t}+\beta_{d} \text { Index_demo }_{i t}+w_{i t}^{\prime} \beta_{w}+\eta_{i}\right),
$$

where $\eta_{i}$ stands for the unobserved time-invariant firm-specific heterogeneity term and $w_{i t}$ is a vector of patent production determinants, as specified in subsection 3.1. Similar to Blundell et al. (2002), we proxy for the unobserved heterogeneity $\eta_{i}$ by arguing that the main source of unobserved permanent differences in firms' capabilities to innovate can be captured by the pre-sample history of innovative successes. In line with that, we assume that the firms' average number of patent applications provides a good approximation of the above unobservable heterogeneity component $\eta_{i}$. However, an overall increase in the number of patent applications is recorded during the pre-sample period. Thus, as Kaiser et al. (2008) suggest, we deal with that by normalizing a firm's number of patents in a presample year by the total number of patents applied for during that year:

$$
\eta_{i}=\frac{1}{T} \sum_{t=\tau}^{T+\tau}\left(\frac{y_{i t}}{\sum_{i=1}^{I} y_{i t}}\right)
$$

Following Blundell et al. (1995), we also include, among the covariates $w_{i t}$, the discounted patent stock of firm $i$ at period $t-1$, in order to account for potential state dependence in patenting activity and to deal with the dynamics of the innovation process, as past patenting activity is very likely to have a positive impact on current patenting activity (Flaig and Stadler 1994). Our measure of state dependence is calculated as:

$$
\text { disc_stock } k_{i t-1}=y_{i t-1}+(1-\delta) \text { disc_stock }_{i t-2},
$$

where $y_{i t-1}$ is the lagged number of patent applications and $\delta$ is the depreciation rate set equal to 30 per cent as in Blundell et al. (1995). State dependence is hence introduced to the model through the term $y_{i t-1}$, the lagged number of patent applications. 
We also add a dummy variable taking value on zero if the firm had never innovated prior to 1995, to capture persistent differences between patenting and non-patenting firms (Blundell et al. 1995, Blundell et al. 1999). In addition, this dummy variable represents a remedy for the so-called "zero-inflation problem" given that in our data many firms never applied for a single patent. The pre-sample information technique is feasible in a study like ours because we have a long series for the dependent variable (1977-1994) prior to the starting period (1995) of the final sample in use.

As described in the identification subsection above, one may argue that the relationship between firm-patenting activity and diversity could be affected by endogeneity. The latter issue might arise because there could be unobserved firm-specific factors influencing both the number of patent applications and the degree of labor diversity. To address these concerns, we apply a two-stage IV procedure to the Poisson model as suggested by Vuong (1984). In this case, equation (1) is specified as follows:

$$
\lambda_{i t}=\exp \left(\beta_{c} \text { Index_ethnic } c_{i t}+\beta_{e} \text { Index_edu } u_{i t}+\beta_{d} I_{n d e x_{-}} \text {demo }_{i t}+w_{i t}^{\prime} \beta_{w}+\eta_{i}+u_{i t}\right)
$$

where the term $u_{i t}$ can be interpreted as unobserved heterogeneity correlated with the diversity indexes but uncorrelated with the vector of patent production determinants $w_{i t} .{ }^{17}$ To model the correlation between the endogenous variables and $u_{i t}$, we specify a system of linear reduced-form equations, one for each diversity index. This is:

$$
\left\{\begin{array}{c}
\text { Index_ethnic } c_{i t}=w_{i t}^{\prime} \gamma_{w}+z_{c t}^{\prime} \gamma_{z}+\varepsilon_{c i t} \\
\text { Index_edu } u_{i t}=w_{i t} \gamma_{w}+z_{c t}^{\prime} \gamma_{z}+\varepsilon_{s i t} \\
\text { Index_demo } o_{i t}=w_{i t}^{\prime} \gamma_{w}+z_{c t}^{\prime} \gamma_{z}+\varepsilon_{d i t}
\end{array}\right.
$$

where $z_{c t}$ is the vector of exogenous variables that affects firm level diversity, but does not directly affect the number of patent applications. As in section 3.1, the excluded variables are the diversity indexes computed at the commuting area where the firm is located and

\footnotetext{
${ }^{17}$ The error term $u_{i t}$ is added to allow for endogeneity. It also induces overdispersion, so that the Poisson model and the Negative binomial model are empirically equivalent.
} 
the model is just-identified. The error terms $\varepsilon$ are assumed to have zero mean and to be correlated across equations for a given firm $i$, but uncorrelated across observations. Furthermore, we assume that the errors $u$ and $\varepsilon$ are related via

$$
u_{i t}=\rho_{c} \varepsilon_{c i t}+\rho_{s} \varepsilon_{s i t}+\rho_{d} \varepsilon_{d i t}+\zeta_{i t}
$$

where $\zeta_{i t} \sim\left[0, \sigma_{\zeta}^{2}\right]$ is independent of $\varepsilon_{c i t}, \varepsilon_{\text {sit }}$ and $\varepsilon_{\text {cit }} .{ }^{18}$ Substituting equation (3) in equation (2) for $u_{i t}$ and taking the expectation with respect to $\zeta$ yields

$E_{\zeta}(\lambda)=\exp \left(\beta_{c}\right.$ Index_ethnic $+\beta_{e}$ Index_edu+ $\beta_{d}$ Index_demo $\left.+w^{\prime} \beta+\eta+\ln E\left(e^{\zeta}\right)+\rho_{c} \varepsilon_{c}+\rho_{s} \varepsilon_{s}+\rho_{d} \varepsilon_{d}\right)$.

The constant term $\ln E\left(e^{\zeta}\right)$ can be absorbed in the coefficient of the intercept as an element of $w$. It follows that

$$
\lambda_{i t}=\exp \left(\beta_{c} \text { Index_ethnic }+\beta_{e} \text { Index_edu }+\beta_{d} \text { Index_demo }+w_{i t}^{\prime} \beta_{w}+\eta_{i}+\rho_{c} \varepsilon_{c i t}+\rho_{s} \varepsilon_{s i t}+\rho_{d} \varepsilon_{d i t}\right)
$$

where $\varepsilon_{c i t}$, $\varepsilon_{\text {sit }}$ and $\varepsilon_{\text {cit }}$ are the new additional variables. Given that the former variables are unobservable, we follow a two-step estimation procedure where we first estimate and generate them and second we estimate parameters of the Poisson model after replacing $\varepsilon_{c i t}, \varepsilon_{\text {sit }}$ and $\varepsilon_{c i t}$ with $\hat{\varepsilon}_{c i t}, \hat{\varepsilon}_{\text {sit }}$ and $\hat{\varepsilon}_{c i t}$. Obviously, the variance and covariance matrix of the two-step estimator needs to be adjusted for the above replacement by bootstrapping the sequential two-step estimator.

Further, as in the analysis on the propensity to innovate, we also include a set of regional, year, industry and year times industry dummies account for potential business cycle influences, regional- or industry-specific effects.

\subsection{Extensive margins}

The estimation approach used to evaluate the extensive margins of firms' patenting behavior is similar to the one adopted for the firms' propensity to patent. Although the

\footnotetext{
${ }^{18}$ This assumption means that $\varepsilon$ is a common latent factor that affects both diversity and patent applications and is the only source of dependence between them, after controlling for the influence of the observed variables.
} 
count data models would be more suitable for the analyses of relationship between workforce diversity and the number of different technological areas of patent application, our data and concretely the lack of minimum observations required to run count data models do not allow us to use them. Instead, we evaluate whether more labor diversity increases the probability of a firm to (apply for a) patent in more than one technological area, conditional on patenting.

\section{$5 \quad$ Results}

This section reports findings for each of the outcome dimensions we look at: propensity to innovate, intensive and extensive margins. Further, we dig deeper into the analyses and we test three main hypotheses, which help us to uncover the role of the mechanisms by which diverse workforces affect firms' innovation outcomes. First, we test the creativity hypothesis proposed by the theoretical frameworks in Hong and Page (2001) and Berliant and Fujita (2011) by distinguishing between diversity among white- and blue-collar workers. Second, we exclude certain groups of foreigners from calculation of ethnic diversity measures to investigate the role of the costs of "cross-cultural dealing" as suggested by Williams and O'Reilly (1998), Zajac et al. (1991) and Lazear (1999). Finally, in the sensitivity analyses subsection we examine whether the results differ across alternative diversity measures and samples.

\subsection{Results on labor diversity and propensity to innovate}

Table 2 reports estimated marginal effects concerning the propensity to apply for a patent in a given year. All the marginal effects of our diversity measures are reported in standard deviation units, to be able to compare the relative contributions of each dimension of diversity, thereby easing the comparison across magnitudes. Moreover, statistical tests of the equality of the marginal effects across dimensions of diversity are included at the bottom of Table 2. In column 1, we show a model with the three workforce diversity indexes as the 
only regressors. The workforce diversity can explain about $14 \%$ of the overall variation in the dependent variable and is associated with sizable and significantly positive effects. Columns 2 show the results from a probit model with all other covariates as described in section 3.1, while columns 3 extends the specification in column 2, by adding an occupational diversity index among the control variables. ${ }^{19}$ By comparing the results of these two columns, we can see that the marginal effects of diversity along the ethnic, educational and demographic dimensions are robust to the inclusion of an occupational diversity index. We can therefore argue that our main diversity measures are not picking up the effect of having occupational heterogeneity at the workplace. While all the former columns treat the diversity indexes as exogenous variables, column 4 shows the results obtained by implementing an IV method, where the predicted workforce diversity levels at commuting areas are used as instruments for the firm workforce diversity. It is important to note that in all IV models we have augmented the specification of column 3, by adding a linear trend interacted with the initial commuting area diversity, as measured in 1990. The results obtained from the IV estimator imply that a standard deviation increase in the ethnic diversity increases the probability to apply for patent by 0.2 percentage points. This corresponds to a rise in the probability to innovate by about 7 percent. $^{20}$ On the contrary, the significance of the effects related to skill/education and demographic diversity vanish. Hypothesis testing also reveals that the marginal effect of ethnic diversity is statistically different from the marginal effect of both educational and demographic diversity. Therefore we can conclude that ethnic diversity matters more than the other two dimensions of diversity. Note that the first stage of our IV approach, reported in Table A1 of Appendix 3, clearly shows that our instruments are strongly correlated with the firm level diversity. Their statistical validity is also confirmed by the F-statistics, as the latter are always above 70, which allows us to dismiss the null hypothesis of weak instrument (Stock and Yogo 2005).

Columns 4 to 6 report models with single diversity dimensions to check whether one

\footnotetext{
${ }^{19}$ The index of occupational diversity is constructed on the first digit classification code of occupation (DISCO) and is based on the Herfindahl index. Its sample mean and standard deviation are 0.692 and 0.229 .

${ }^{20}$ These figures are obtained using the average probability of innovating. From the estimates in Table 2, the average probability of innovating is around 0.03 . Therefore, the changes in the probability of innovating, in percentage terms, are $(0.2 / 0.03)=6.66$.
} 
dimension of diversity captures the effects associated with other indexes. Ethnic diversity, for example, may pick up some of the skill diversity effects as individuals with the same education but coming from different countries may present degrees of educational heterogeneity as well. Both educational and demographic diversity remains insignificant even when they enter the probit model separately while the coefficient of ethnic diversity remains stable. We cannot, however, rule out that the ethnic diversity is still capturing heterogeneity in a specific educational level (employees with same degree but coming from different universitary systems may still present some degree of heterogeneity).

Turning to the other control variables, firms with higher shares of highly skilled and vocational workers, and exporting firms have higher propensity to patent. Instead, the knowledge spillovers and the average firm tenure do not explain much of such a propensity.

As mentioned in section 2.2, we additionally estimate probit models using diversity indexes based on a more detailed category specification; the results are shown in the Table 2 , columns 8,9 and 10. As in the aggregate specification, also in this one we find that our measures of diversity are robust to the inclusion of an occupational diversity index and that applying our IV strategy only ethnic diversity seems to matter in terms of the propensity to innovate. A standard deviation change in the ethnic diversity produces an increase in the probability to apply for a patent by 0.1 percentage points which correspond to a rise in the probability to innovate by 3 percent, whereas the effects of education and demographic diversity appear negligible. ${ }^{21}$

Our findings differ from Østergaard et al. (2011), which also investigates the relationship between labor diversity and firm's innovation in the Danish context, because of differences in data and estimation methods employed. Although Østergaard et al. (2011) use the same employer-employee data set, they focus only on the year 2002 for the computation of diversity indexes. Whereas our dependent variable is whether the firm applies for a patent at EPO, theirs is defined as the introduction of a new product or service, which is retrieved from survey data. This implies that the sample sizes in the two studies are too far to be comparable: 96,636 versus 1,648. Compared to our study, Østergaard et al. (2011) do

\footnotetext{
${ }^{21}$ Results obtained from the specifications with single diversity dimensions are very similar to the ones reported in columns 5, 6 and 7 and are available on request from the authors.
} 
not include proxies for firm unobservables and don't control for the workforce composition; furthermore they do not deal with potential endogeneity issues.

\subsection{Results on labor diversity and intensive margins}

In the next step, we analyze how workforce diversity contributes to the number of patent application. Tables 3 reports the results of the intensive margins analyses, here the estimated coefficients represent elasticities. The first column in Table 3 shows the output of a Poisson regression ${ }^{22}$ having only the diversity measures as regressors: the coefficients to all diversity indexes are large, positive and significant. Once more, after including all the other control variables (column 2) their dimension and statistical significance decreases but are robust to the inclusion of an occupational diversity (column 3). Both in columns 2 and 3 , hypothesis testing does not allow us to conclude that the estimated elasticities to our measures of diversity are statistically different from each other. In our preferred specification (column 4) though we find that only the effect of ethnic diversity is precisely estimated and that a ten percent increase in the latter index leads to 4 percent increase in the number of patent applications for the aggregated diversity measures. This effect is quite sizable given that the elasticity associated with an important production input, like human capital (proxied by the share of highly skilled workers) is of comparable magnitude. Similar conclusions are drawn when all the diversity indexes enter separately the Poisson equation. As in the previous section, our first stage results confirm that our instruments are very good predictors of the firm level diversity. ${ }^{23}$

In line with previous literature, we find important effects of the shares of highly skilled workers, capital and labor stock on the number of patent applications, whereas knowledge spillovers do not seem to have significant contributions to the overall number of patent applications. As in the case of patenting propensity, exporters benefit from the knowledge gained on the international markets.

Columns 7 and 8 in Table 3 report results for models using the labor diversity indexes

\footnotetext{
${ }^{22}$ Negative binomial models provide very similar results which are available on request from the authors.

${ }^{23}$ The results from the first stage are reported in Table A2 of Appendix 3.
} 
based on disaggregate groupings. The results are similar to those using aggregate diversity specifications, although the coefficients to our diversity variables are slightly smaller in size. Specifically, the IV Poisson estimations (column 10) reveal that only the coefficient to ethnic diversity is precisely estimated and that a ten percent increase in this index implies a 2.2 percent increase in the number of patent applications. ${ }^{24}$

\subsection{Results on labor diversity and extensive margins}

Table 4 reports the effects of labor diversity on the probability of patenting in different technological areas in a given year, conditional on patent application. The structure of this table is similar to the previous one and all the marginal effects of diversity measures are reported in standard deviation units, to ease the comparison across magnitudes. Regarding the variables of interest, we find that the diversity indexes alone explain 7 percent of the overall variation in the dependent variable and that the coefficients to both ethnic and educational diversity indexes are positive and statistically significant and robust to the inclusion of all the other controls (column 2) and of an occupational diversity index (column 3). However, the significance of the diversity in skill/education vanishes when endogeneity is taken care of and hypothesis testing indicates that ethnic diversity matters more than educational diversity in terms of patenting in different technological areas (column 4). More specifically, our IV results indicate that a standard deviation increase in ethnic diversity is associated with a raise of about 14 (31) percent points in the probability to patent in different technological fields for the aggregate (disaggregate) diversity, conditional on patent application. Or alternatively, a standard deviation increase in ethnic diversity almost duplicates the probability to patent in different technological fields, according to the most conservative estimates. ${ }^{25}$ Thus, the fact that cultural diversity is much more relevant for

\footnotetext{
${ }^{24}$ We have also investigated whether the effects of a particular dimension of diversity can be influenced by other forms of labor heterogeneity by inclusion of all possible interaction couples between the diversity indexes. Furthermore, driven by the hypothesis that there might be complementarities among different skills and demographic groups, in particular young and educated workers together with a more diverse workforce can stimulate innovation and creativity, we have augmented our models with interactions between diversity indexes and shares of highly skilled and younger workers. Nevertheless, none of the interactions turned out to be statistically significant. Figures showing marginal effects of the interactions are available from the authors upon request.

${ }^{25}$ From the estimates in Table 4, the average probability of patenting in different technological areas is
} 
patenting in different technological areas rather than for the patenting per se is somehow plausible as a diversified portfolio of patent applications might reflect a substantial degree of knowledge heterogeneity and hence skill complementarity.

Turning to the other control variables, firms with higher shares of highly skilled and young workers, and larger capital stock have higher probability of patenting in different technological areas.

\subsection{Results - mechanisms involved}

Our rich dataset allows us to uncover the role of different mechanisms by which diverse workforces affect firms' innovation outcomes as proposed by the theory and thus we test a number of hypotheses. Firstly, we calculate our diversity indexes for white- and blue-collar occupations separately. This is driven by the idea that diversity could play a different role for distinct occupational groups and consequently have diverse effects on firm innovation. In particular, we expect that the beneficial effects of diverse problem-solving abilities and creativity would materialize more in terms of innovation for white-collar occupations compared to blue-collar occupations. Second, we exclude certain groups of foreigners from calculation of ethnic diversity measures to test how important are the communication costs and costs of "cross-cultural dealing". In these analysis and those reported in the next section, we use disaggregate indexes only, as we think that the indexes based on a detailed categorization may be more adequate to represent workforce diversity. ${ }^{26}$ Moreover, all results are obtained by estimating the full IV specification described in the previous section.

The results of the effect of diversity indexes calculated separately for the two occupational groups on firm probability to innovate, number of patent applications and firm probability of applying for a patent in different technological areas are presented in the first two columns of Table 5. Our results show that that workforce ethnic diversity is indeed much more important for white-collar than for blue-collar occupations. Hypothesis testing around 0.18 . Therefore, the changes in the corresponding probability, in percentage terms, are $(14 / 0.18)=$ 77 .

${ }^{26}$ The results using the aggregate indexes are qualitatively similar to the detailed categorization and are reported in Tables A3-A5 of Appendix 3. 
always reveal that the coefficient of ethnic diversity calculated for white-collar workers is statistically different than the corresponding coefficient for blue collar workers. ${ }^{27}$ The effect of ethnic diversity on both the intensive and extensive margins of innovation is positive and statistically significant for the group of white-collar workers only. Conversely, the effect of education and demographic diversity is insignificant for both white- and blue-collar occupations. Thus, our results support the creativity hypothesis proposed by the theoretical frameworks by Hong and Page (2001) and Berliant and Fujita (2011), at least for ethnic diversity.

To test the role of "cross-cultural dealing" we exclude from the calculation of ethnic diversity alternative groups of foreigners: (1) the second generation immigrants, who are very likely to be fluent in Danish and who are almost perfectly integrated into the Danish society and culture; (2) foreigners with tertiary education and (3) foreigners speaking one of the language belonging to the germanic group. The last two groups are likely to absorb Danish or English (which is the communication language in many businesses in Denmark) more quickly. It is plausible to expect that communication costs associated with ethnic diversity may increase after subtracting out foreigners who are likely to speak Danish or English. The results are shown in Table 5, columns 3, 4 and 5 for measures treating the second generation of immigrants, foreigners with a language belonging to the Germanic group of languages and foreingers with university education as natives, respectively. Interestingly, the role of ethnic heterogeneity on innovation weakens once we exclude foreigners who probably speak English or Danish, confirming the idea that the communication costs and costs of "cross-cultural dealing" are likely to be more important when foreigners don't speak the same language. This is shown by results of analyses from all innovation outcomes under consideration. Furthermore, the fact that the effect of ethnic diversity on the number of patent applications remains positive and significant even when we exclude university graduates may also indicate that the latter effects are not merely driven by the recruitment of talented high skilled workers from abroad.

\footnotetext{
${ }^{27}$ The chi2 (p-value) are respecitvely $29.64(0.000), 4.79 ; 0.047: 34.78(0.000)$ in the regressions for firm probability to innovate, number of patent applications and firm probability of applying for a patent in different technological areas.
} 


\subsection{Sensitivity analyses}

In this section, we examine whether the effects of labor diversity on patenting activity of firms hold across alternative diversity measures and samples. All results are again based on the full IV specification described in the previous section and they are shown in Tables 6 and 7.

First, as a part of the sensitivity analysis we evaluate eventual variations in the effects of labor diversity when the diversity measure is differently computed. In particular, we use two alternative diversity indexes: the Shannon-Weaver entropy and the richness indexes. The entropy index is considered as one of the most profound and useful diversity indexes in biology (Maignan et al. 2003), whereas the richness index is defined as a number of categories observed for each dimension of interest (it does not account for the "evenness" dimension). The results are shown in Table 6, columns 1 and 2, respectively, and both measures support the results from our main analyses using our preferred Herfindhal index and show that ethnic diversity has significant positive effect on all considered innovation outcomes.

Next, we include an Herfindhal index for the type of tertiary education (this index has now only 4 categories: engineering, natural sciences, social sciences and humanities) and the standard deviation for the years of education and age. This allows us, on one hand, to treat age as a cardinal variable and, on the other, to disantangle the effects associated with the amount of education from those related to the type of tertiary education. The results from Table 6, column 3, show that the effects of both education and demographic diversity are never significant.

Next, we run our analyses using an alternative instrument for the workplace ethnic diversity based on shares of immigrants at the commuting areas predicted from a model of migration determinants, as described in section 4.2 above. Specifically, we use the model of migration determinants to predict shares of immigrants from a particular source country living in a particular commuting area. We then use the predicted shares of immigrants to 
construct ethnic diversity levels at commuting areas, which we then use as an instrument for ethnic diversity on the workplace level. Diversity in the other two dimensions, i.e. educational and demographic, is instrumented as in the main analysis, i.e. by using the historical composition and the current population stocks of the labor supply at the commuting area level. The results using the alternative IV shown in column 4, Table 6, confirm our main findings. For all three studied innovation outcomes we observe that the ethnic diversity has a significantly positive effect, whereas the effects of educational and demographic diversity are statistically insignificant.

We also look at whether there is any difference in the effect of diversity on innovation for firms with or without pre-sample patents. Not surprisingly, the last two columns of Table 6 show that the impact of ethnic diversity is stronger for firms with pre-sample patents, especially in the regressions where the probability to innovate is the outcome variable.

As big cities have usually a lot of immigrants and at the same time a high percentage of innovative firms, in the next robustness check we drop Copenhagen (the only real agglomeration area in Denmark) and environs from the analysis. Results from this robustness check are reported in column 1 of Table 7 , and do not qualitatively differ from the main results.

In the main analysis our labor diversity measures have been obtained as weighted averages of Herfindahl indexes computed at the workplace level. Given that 11 percent of firms are multi-establishment companies, we test the robustness of our results: i) by constructing a single-firm level metric rather than using the weighted approach to measure diversity as described in section 3.2 , ii) by excluding multi-establishment enterprises from the sample. Columns 2 and 3 of Table 7 report information on these robustness checks: the interpretation of these findings does not substantially differ from the main results.

Finally as our diversity measures are likely to have some mechanical link to firm size, we have divided firms by size and evaluate whether there is any change in the coefficients of workforce diversity for small firms (those with fewer than 50 employees), medium-sized firms (those with 50-100 employees) and large firms (those with more than 100 employees). As reported in Table 7, columns (4)-(6), the coefficients of the ethnic diversity index are significantly positive for all size categories, with the largest coefficient associated with large 
firms. As in the main analysis, diversity in the other two dimensions is never statistically significant.

\section{Conclusions}

In this paper we provide evidence of the nexus between labor diversity and firms' patenting behavior. Our study represents an attempt to generalize the relationship between labor diversity and innovation by using detailed information on firms' workforce composition. In fact, our final sample is the result of a merge of the Danish linked employer-employee data with the register of firms' business accounts and a collection of patent applications sent to the European Patent Office (EPO) by Danish firms.

In our empirical analysis, we (a) control for a large number of firm-specific characteristics referring to the workforce (average firm tenure, shares of foreigners from different group of countries or languages, males, workers with either tertiary or secondary education, workers with different occupation, employees belonging to different age groups) or to whether the firm is exporter, foreign owned and multi-plant; (b) add at least to the equation of intensive margins the discounted patent stock and a dummy for past patenting firm status to proxy for firm time-invariant unobservables and hence to deal with firm heterogeneity (Blundell et al. 1995; Blundell et al. 1999); (c) include reasonable measures of knowledge spillovers based on geographical and technological proximity between firms to take into account the influence of external sources of knowledge in firm innovation outcome (Audretsch and Feldman 1996, Adams and Jaffe 1996); (d) implement an IV strategy grounded on the historical composition of the labor force at the commuting area level (Card and Di Nardo 2000, Dustmann et al. 2005, Cortes 2008, Foley and Kerr 2012); (e) adopt alternative categorizations (aggregate and disaggregate) and different measures (Herfindahl, Shannon-Weaver and richness) of diversity as sensitivity tests. However, our study presents some limitations that further research may address. Most importantly, we could not implement panel estimation approaches, that would have better controlled for firm time-invariant unobservables, due to insufficient data variation. Furthermore, the lack of detailed information on the traits of 
innovations prevent us from investigating whether ethnic diversity plays an important role in terms of the quality of innovation.

Our results broadly support the hypothesis that ethnic diversity of the labor force is an important source of innovation. Ethnic diversity seems to facilitate firms' patenting activity in several ways by: (a) increasing the propensity to (apply for a) patent; (b) increasing the overall number of patent applications and (c) enlarging the breadth of patenting technological fields, conditional on patenting. Being prudent in the quantification of ethnic heterogeneity effects on all these aspects of patenting activities, we find that a 10 percentage change in ethnic diversity increases the number of firms' patent applications by approximately 2.2 percent, according to the most conservative estimates. The contribution of ethnic diversity in terms of general propensity to send at least one patent application in a given year is economically sound: a standard deviation change in its value turns to raise such a probability by 3-7 percent. Conditional on patenting, the effect of ethnic diversity on extensive margins is very large, a standard deviation change in skill diversity almost duplicates the firms' probability to apply for a patent in different technological areas. Thus, in order to widen the patent technological spectrum it seems to be fundamental to increase the heterogeneity in the workers' knowledge stemming from diverse cultural backgrounds. This comes as no surprise as a diversified portfolio of patent applications most likely reflects a variety of perspectives, heuristics, skills and ideas that complement each other.

Regarding the results of education and demographic diversity on innovation, their effects typically vanish when we include the full set of controls or once we instrument the diversity measures. Finally, we find that the beneficial effect of ethnic diversity on innovation materializes for white-collar occupations only, whereas the effect for the group of blue-collar workers is negligible. These results support the hypothesis that more educated workers tend to have a wider pool of different experiences, knowledge bases and heuristics boosting their problem-solving capacities and creativity, which in turn facilitate innovations. In this regard, our findings are consistent with the theoretical frameworks proposed by Hong and Page (2001) and Berliant and Fujita (2011).

The overall picture coming out from our empirical analyses seems to be particularly 
relevant not only for the design of firms' innovation and hiring strategies but also for public policies aimed at fostering innovation. Our results give an important insight into the technological process, a driver of productivity growth and hence of the economic growth. We find that an increase in firm labor diversity in terms of ethnicity has a positive effect on the firm innovation process. Thus, governmental policies aimed to promote an employment of workers with different cultural backgrounds can be beneficial in terms of improvements in firms' patenting activities, increasing both private returns, directly, and social gains, through knowledge diffusion mechanisms. Such policies might help to invert the general decline in patenting activity recorded during the recent economic crisis among the OECD countries (OECD 2009 and 2011). 


\section{Acknowledgments}

We thank Guglielmo Barone, Tor Eriksson, Hideo Owan, Pekka Ilmakunnas, Michael Rosholm, Chad Syverson and Måns Soderbom (alphabetical order) for helpful suggestions. In addition, we appreciate comments from participants at seminars organized by the Copenhagen Business School, University of Bergamo, Aarhus School of Business, University of Lausanne, and from participants at the following conferences: ESPE 2010, The 5th Nordic Summer Institute in Labor Economics, The 2010 Ratio Young Scientist Colloquium, ESEM 2010, CAED/COST 2010 in London, the 2010 International Symposium on Contemporary Labor Economics at WISE, Xiamen, and EALE 2011 in Paphos. We also thank Ulrich Kaiser and Cedric Schneider for graciously providing us the data on patent applications. Pierpaolo Parrotta acknowledges the financial support from the Swiss National Centre of Competence in Research LIVES and Graduate School for Integration, Production and Welfare. Mariola Pytlikova gratefully acknowledges funding from the NORFACE programme on "Migration in Europe - Social, Economic, Cultural and Policy Dynamics" (project MI3, "Migration: Integration, Impact and Interaction"). The usual disclaimer applies. 


\section{References}

[1] Adsera A, Pytlikova M (2012) The Role of Language in Shaping International Migration: Evidence from OECD Countries 1985-2006. IZA Discussion Paper 6333, Bonn: IZA Institute for the Study of Labour.

[2] Alcacer J, Wilburg C (2010) Location Strategies for Agglomeration Economies. HBS Working Paper 10-071, Harvard Business School, Boston.

[3] Andersen AK (2000) Commuting Areas in Denmark. AKF Working paper, Copenhagen.

[4] Audretsch DB, Feldman MP (1996) R\&D Spillovers and the Geography of Innovation and Production. American Economic Review 86(3): 630-40.

[5] Adams JD (1990) Fundamental Stocks of Knowledge and Productivity Growth. Journal of Political Economy 98: 673-03.

[6] Adams JD, Jaffe A (1996) Bounding the Effects of R\&D: An Investigation Using Linked Establishment and Firm Data. RAND Journal of Economics 98: 673-02.

[7] Anderson R, Quigley JM, Wilhelmsson M (2005) Agglomeration and the spatial distribution of creativity. Papers in Regional Science 83: 445-64.

[8] Archibugi D, Pianta M (1996) Measuring technological change through patents and innovation surveys. Technovation 16: 451-519.

[9] Bantel KA, Jackson SE (1989) Top Management and Innovations in Banking: Does the Composition of the Top Team Make a Difference? Strategic Management Journal 10: $107-24$.

[10] Basset-Jones N (2005) The Paradox of Diversity Management, Creativity and Innovation. Creativity and Innovation Management 14: 169-75.

[11] Becker GS (1957) The Economics of Discrimination. University of Chicago Press, Chicago. 
[12] Berliant M, Fujita M (2011) The dynamics of knowledge diversity and economic growth. Southern Economic Journal 77: 856-884.

[13] Bloom N,Van Reenen J (2002) Patents, real options and firm performance. Economic Journal 112: 97-116.

[14] Blundell R, Griffith R, Van Reenen J (1995) Dynamic Count Data Models of Technological Innovation. Economic Journal 105: 333-44.

[15] Blundell R, Griffith R, Van Reenen J (1999) Market Share, Market Value and Innovation in a Panel of British Manufacturing Firms. The Review of Economic Studies 66: $529-54$.

[16] Blundell R, Griffith R, Windmeijer F (2002) Individual Effects and Dynamics in Count Data Models. Journal of Econometrics 108: 113-31.

[17] Card D, DiNardo JE (2000) Do Immigrant Inflows Lead to Native Outflows? American Economic Review: Papers and Procedures 90: 360-67.

[18] Card D (2001) Immigrant inflows, native outflows, and the local labor market impacts of higher immigration. Journal of Labor Economics 19(1): 22-64.

[19] Cortes P (2008) The Effect of Low-Skilled Immigration on U.S. Prices: Evidence from CPI Data. Journal of Political Economy 116 (3): 381-22.

[20] Cohen WM, Levinthal DA (1990) Absorptive Capacity: A New Perspective on Learning and Innovation. Administrative Science Quarterly 5: 128-52.

[21] Damm, AP (2009) Ethnic Enclaves and Immigrant Labor Market Outcomes: QuasiExperimental Evidence. Journal of Labor Economics, 27(2): 281-14.

[22] Dawson J (2012) Measurement of work group diversity. Ph.D. Thesis. Aston University, Birminghan. http://eprints.aston.ac.uk/16437.

[23] Deding M, Filges T., Van Ommeren J (2009) Spatial Mobility and Commuting: the Case of Two-Earner Households. Journal of Regional Science 49: 113-47. 
[24] Delgado M, Porter M, Stern S (2010) Clusters and Entrepreneurship. Journal of Economic Geography 10: 495-18.

[25] Drach-Zahavy A, Somech A (2001) Understanding Team Innovation: The Role of Team Processes and Structures. Group Dynamics: Theory, Research, and Practice 5(2): 11123.

[26] Dustmann C, Fabbri F, Preston I (2005) The impact of immigration on the British labour market. Economic Journal 115(507): F324-F341.

[27] European Commission (2005) The Business Case for Diversity: Good Practices in the Workplace. Brussels. http://ec.europa.eu/social/main.jsp?catId $=780$

[28] Feldman MP, Audretsch DB (1999) Innovation in Cities: Science-Based Diversity, Specialization and Localized Competition. European Economic Review 43: 409-29.

[29] Foley CF, Kerr WR (2011) Ethnic innovation and US multinational firm activity. National Bureau of Economic Research Working Paper 17336. Cambridge (MA).

[30] Frederiksen A, Kato T (2011) Human capital and career success: Evidence from linked employer-employee data. IZA Discussion Papers 5764. Bonn: IZA Institute for the Study of Labour.

[31] Griliches Z (1990) Patent Statistics as Economic Indicators: A Survey. Journal of Economic Literature 28: 1661-07.

[32] Hall BH, Jaffe A, Trajtenberg M (2005) Market Value and Patent Citations. RAND Journal of Economics 36: 16-38.

[33] Harrison DA, Klein KJ (2007) What's the difference? Diversity constructs as separation, variety, or disparity in organizations. Academy of Management Review 32: $1199-28$.

[34] Hatzigeorgiou A, Lodefalk M (2011) Trade and Migration: Firm-Level Evidence. Department of Economics Working paper, Lund University, Lund. 
[35] Hiller S (2013) Does immigrant employment matter for export sales? Evidence from Denmark. Review of World Economics: 1-26.

[36] Hong L, Page SE (2001) Problem Solving by Heterogeneous Agents. Journal of Economic Theory 97 (1): 123-63.

[37] Horwitz SK, Horwitz IB (2007) The Effects of Team Diversity on Team Outcomes: A Meta-Analytic Review of Team Demography. Journal of Management 33: 987-15.

[38] Jaffe AB (1986) Technological Opportunity and Spillovers of R\&D. American Economic Review 76: 984-01.

[39] Jost L (2006) Entropy and diversity. Oikos 113: 363-374.

[40] Kaiser U, Kongsted H, Rønde T (2008) Labor Mobility and Patenting Activity. Centre for Economic and Business Research (CEBR), Copenhagen.

[41] Kerr WR, Lincoln W (2010) The Supply Side of Innovation: H-1B Visa Reforms and US Ethnic Invention. Journal of Labor Economics 28: 473-08.

[42] Kelley MR, Helper S (1999) Firm Size and Capabilities, Regional Agglomeration, and the Adoption of New Technology. Economics of Innovation and New Technology 8: 79-03.

[43] Knight D, Pearce CL, Smith KG, Olian JD, Sims HP, Smith KA, Flood P (1999) Top management team diversity, group process, and strategic consensus. Journal of Strategic Management 20: 445-65.

[44] Krugman P, (1991) Geography and Trade. MIT Press, Cambridge MA.

[45] Lanjouw JO, Pakes A, Putnam J (2003) How to count patents and value intellectual property: The uses of patent renewal and application data. The Journal of Industrial Economics 46.4: 405-432.

[46] Lazear EP (1998) Personnel Economics for Managers. New York: John Wiley \& Sons. 
[47] Lazear EP (1999) Globalisation and the Market for Team-Mates. The Economic Journal 109: $15-40$.

[48] Maignan C, Ottaviano G, Pinelli D, Rullani F (2003) Bio-Ecological Diversity vs. SocioEconomic Diversity: A Comparison of Existing Measures. Fondazione Eni Enrico Mattei, Nota di Lavoro 13, Milan.

[49] Montgomery JD (1991) Social Networks and Labor Market Outcomes: Toward an Economic Analysis. American Economic Review 81: 1408-18.

[50] Munshi K (2003) Networks in the Modern Economy: Mexican Migrants in the US Labor Market. The Quarterly Journal of Economics 118: 549-99.

[51] Nathan M (2012) Same Difference? Ethnic Inventors, Diversity and Innovation in the UK. Mimeo London School of Economics and Spatial Economics Research Centre.

[52] Niebuhr A (2010) Migration and innovation: Does cultural diversity matter for regional R\&D activity? Papers in Regional Science 89: 563-85.

[53] OECD (2009) Policy responses to the Economic crisis. Investing in Innovation for LongTerm Growth. Paris. http://www.oecd.org/dataoecd/59/45/42983414.pdf

[54] OECD (2011) Innovation in the crisis and beyond. Paris. http://www.oecd.org/sti/stioutlook-2012-chapter-1-innovation-in-the-crisis-and-beyond.pdf

[55] Ortega F, Peri G (2009) The Causes and Effects of International Migrations: Evidence from OECD Countries 1980-2005. National Bureau of Economic Research Working Paper 14833. Cambridge (MA).

[56] Osborne E (2000) The Deceptively Simple Economics of Workplace Diversity. Journal of Labor Research 21: 463-75.

[57] Ozgen C, Nijkamp P, Poot J (2011a) Immigration and Innovation in European Regions. IZA Discussion Paper 5676. Bonn: IZA Institute for the Study of Labour. 
[58] Ozgen C, Nijkamp P, Poot J (2011b) The impact of cultural diversity on innovation: Evidence from Dutch firm-level data. IZA Discussion Paper 6000. Bonn: IZA Institute for the Study of Labour.

[59] Parrotta P, Pozzoli D, Pytlikova M (2011) Does Labor Diversity Affect Firm Productivity? Norface Migration Discussion Paper No. 2011-5, London.

[60] Pedersen PJ, Pytlikova M, Smith N (2008) Selection and Network Effects - Migration Flows into OECD Countries 1990-2000. European Economic Review 52(7): 1160-86.

[61] Pitcher P, Smith AD (2001) Top Management Team Heterogeneity: Personality, Power, and Proxies. Organization Science 12(1):1-18.

[62] Stock JH, Yogo M (2005) Testing for weak instruments in linear IV regression. In D.W.K. Andrews and J.H. Stock (eds.), Identication amd inference for econometric models: Essays in honour of Thomas Rothenberg. Cambridge University Press, Cambridge MA.

[63] Söllner R (2010) Human Capital Diversity and Product Innovation: A Micro-Level Analysis. Jena Economic Research Papers 2010-027, Friedrich-Schiller-University Jena, Max-Planck-Institute of Economics, Jena.

[64] Trajtenberg M (1990) A penny for your quotes: patent citations and the value of innovations. The Rand Journal of Economics 21, 172-187.

[65] Vuong QH. (1984) Two-Stage Conditional Maximum Likelihood Estimation of Econometric Models. California Institute of Technology, Social Science Working Paper 538. Pasadena CA.

[66] Wallsten SJ (2001) An Empirical Test of Geographic Knowledge Spillovers Using Geographic Information Systems and Firm-Level Data. Regional Science and Urban Economics 31(5): 571-99. 
[67] Watson WE, Kumar K, Michaelsen LK (1993) Cultural Diversity's Impact on Interaction Process and Performance: Comparing Homogeneous and Diverse Task Groups. The Academy of Management Journal 36 (3): 590-02.

[68] Williams KY, O'Reilly III CA (1998). Demography and Diversity in Organizations: A Review of 40 Years of Research. Research in Organizational Behavior 20: 77-40.

[69] Østergaard CR, Timmermans B, Kristinsson K (2011) Does a different view create something new? The effect of employee diversity on innovation. Research Policy 40(3): $500-509$.

[70] Zajac E, Golden BR, Shortell SM (1991) New Organizational Forms for Enhancing Innovation: The Case of Internal Corporate Joint Ventures. Management Science 37(2): $170-84$. 


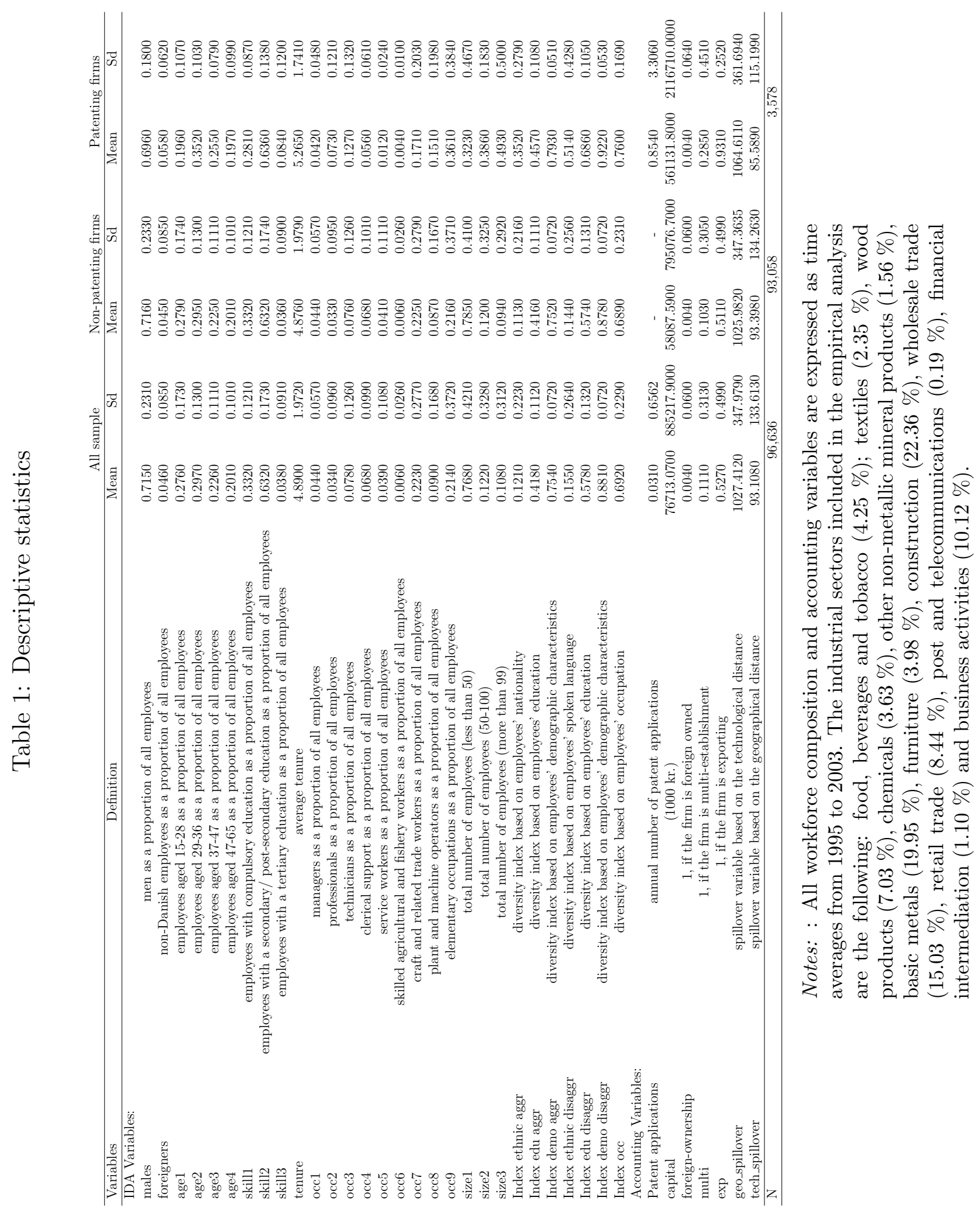




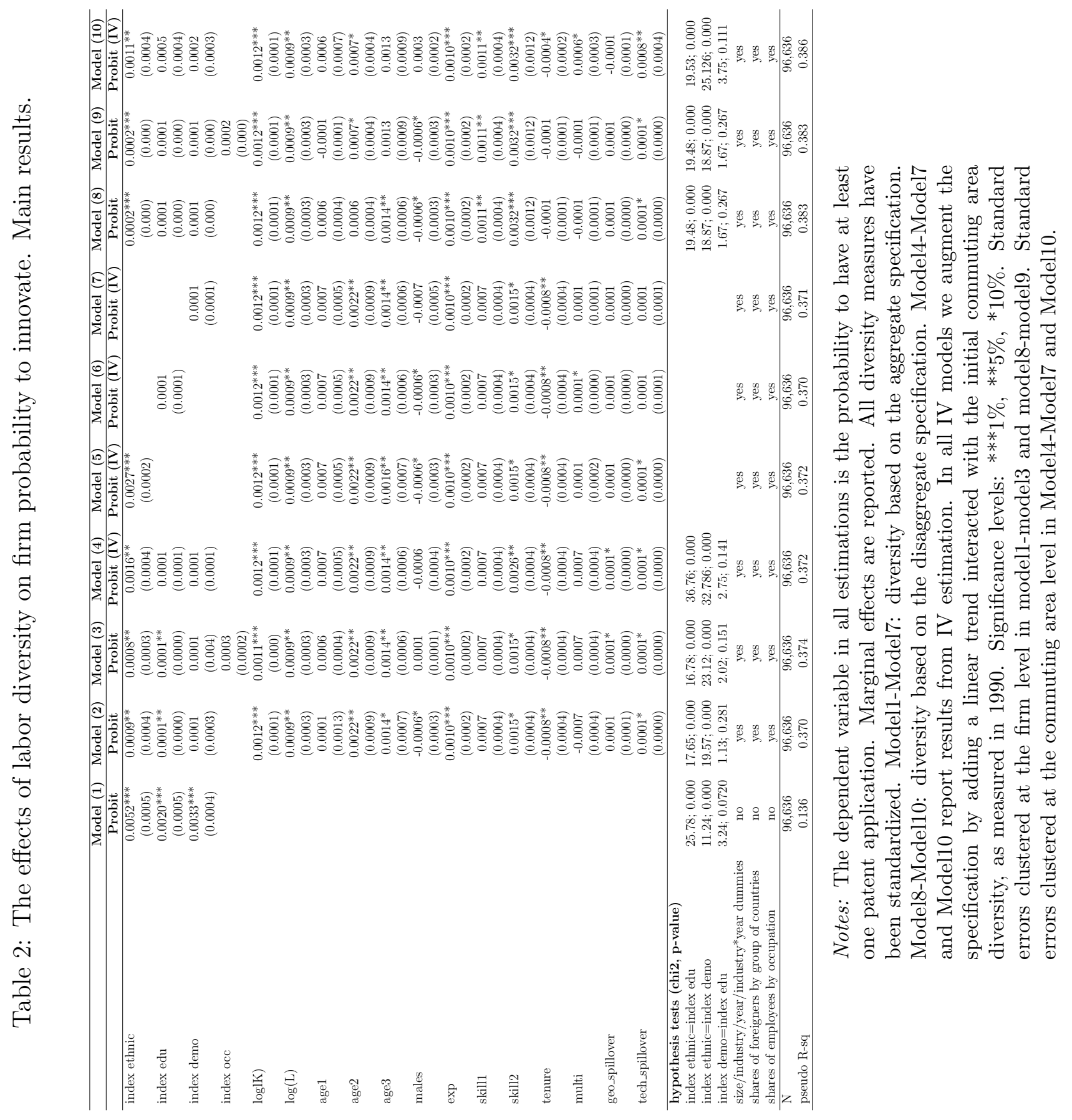




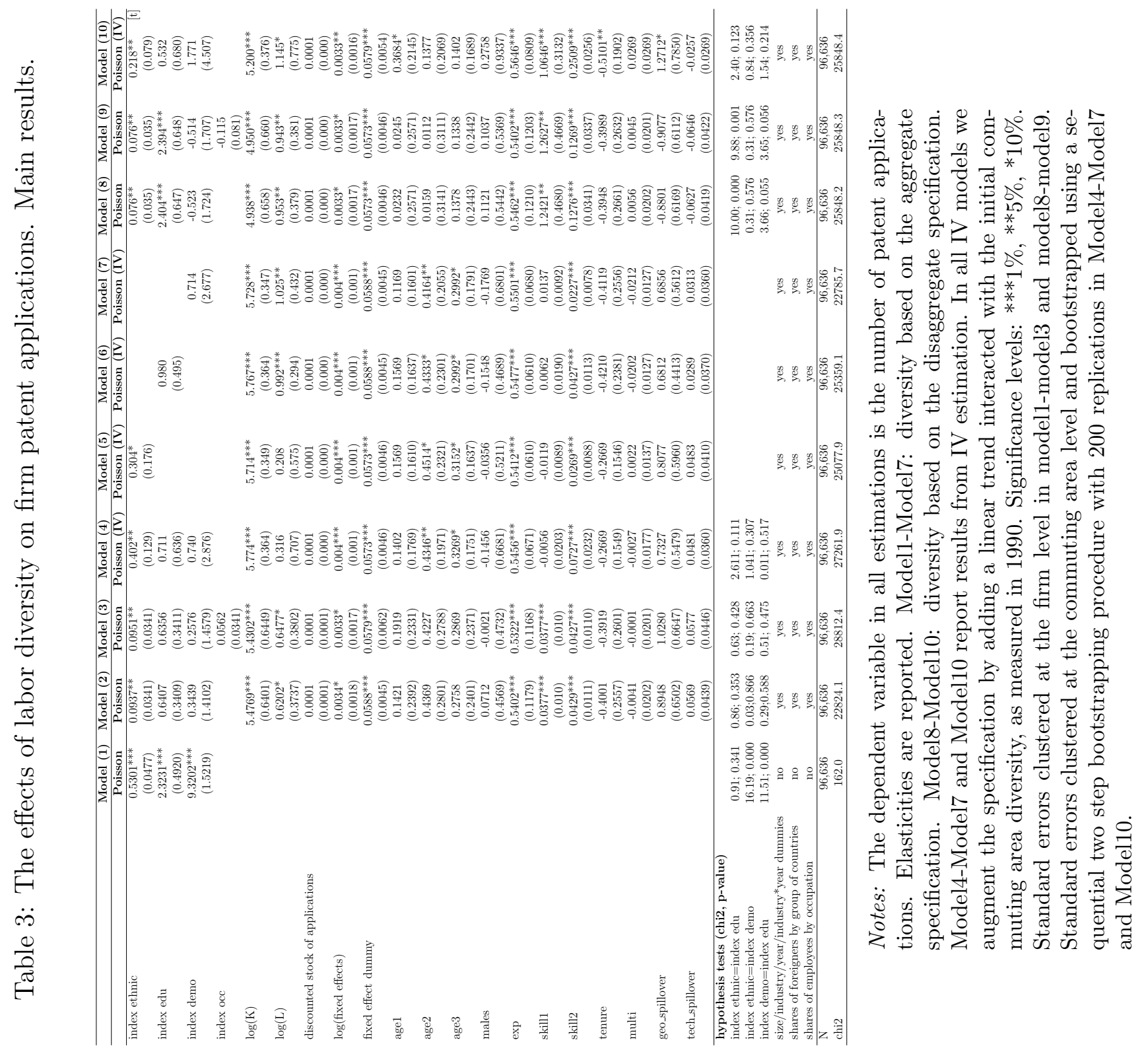




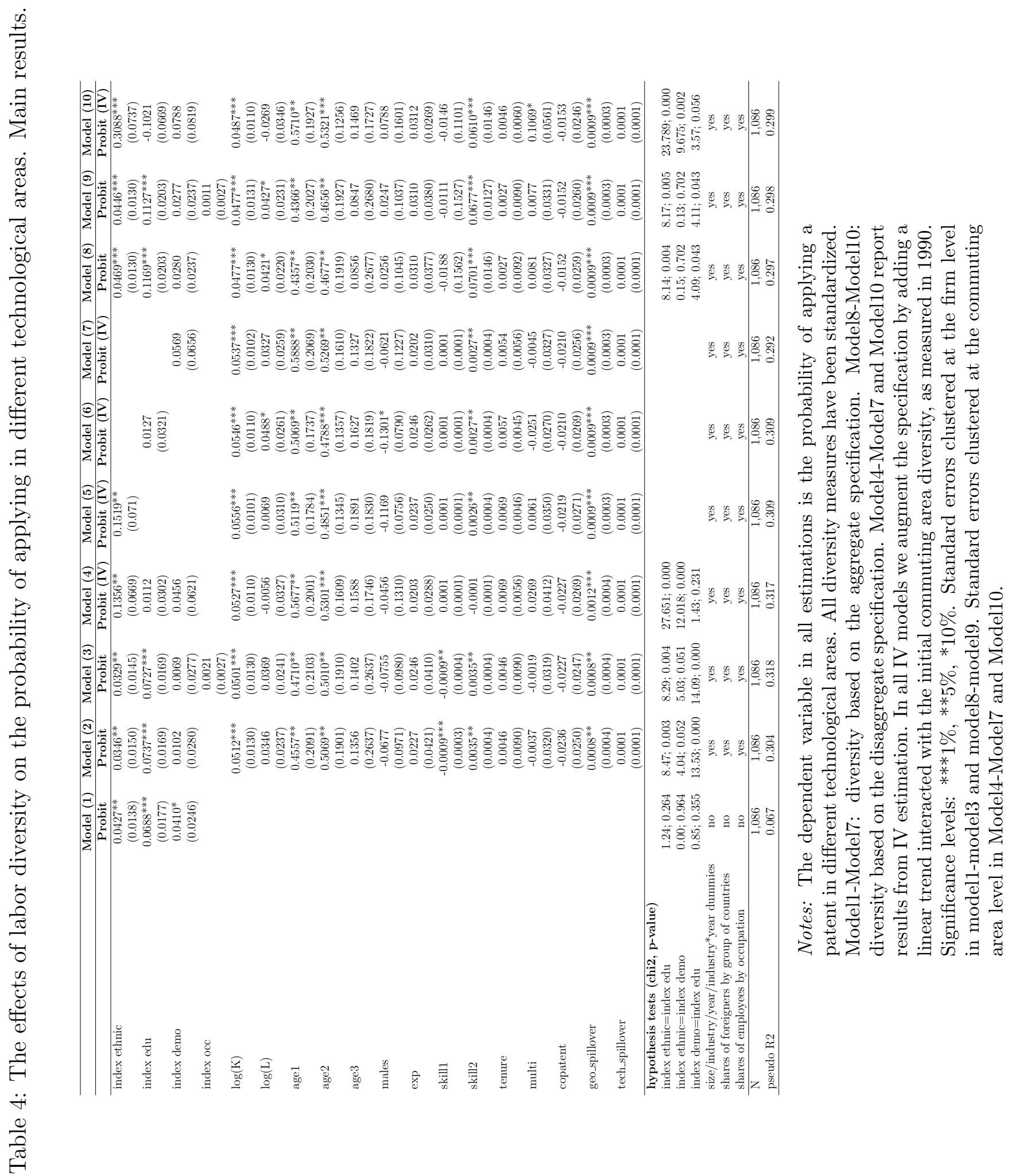




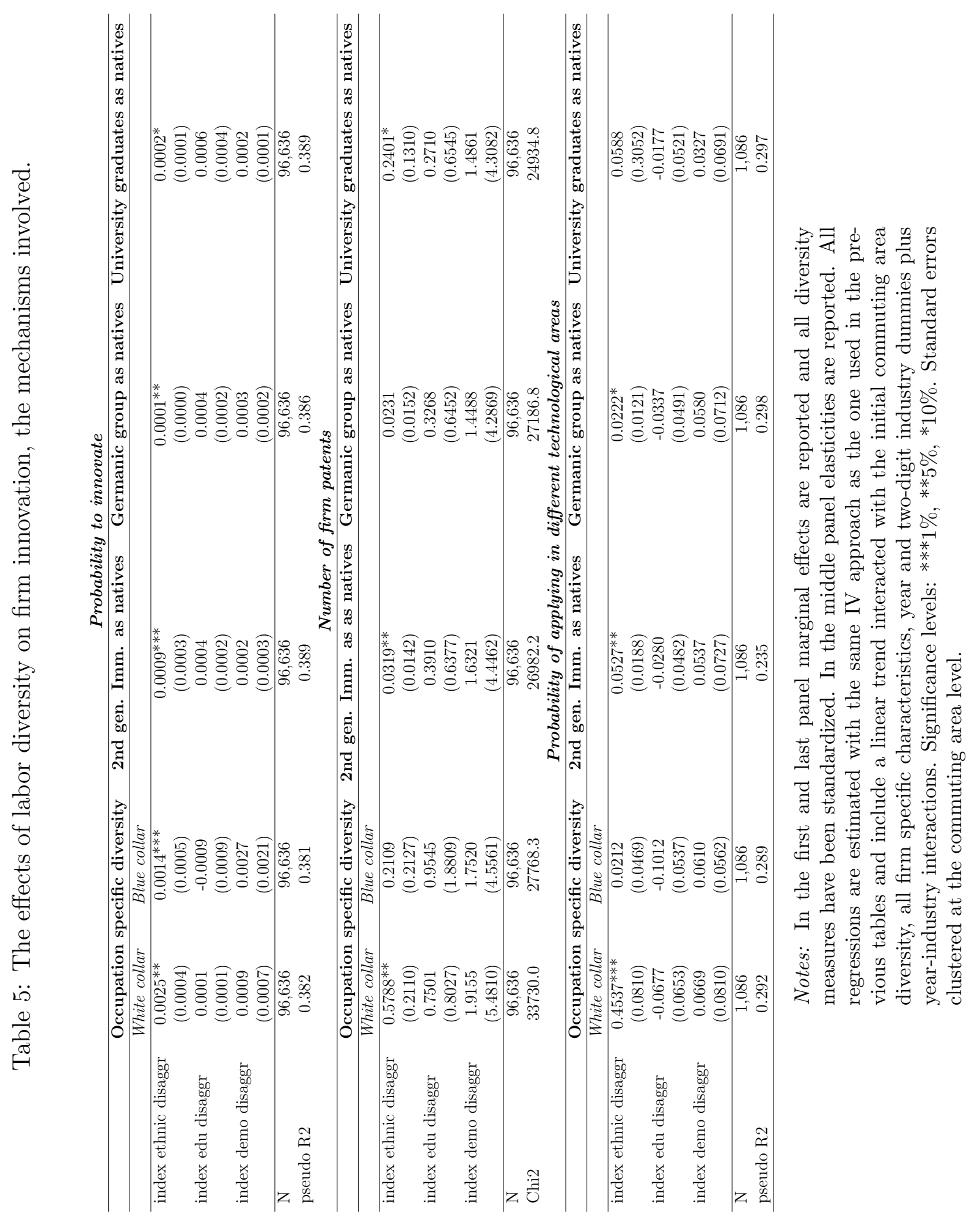




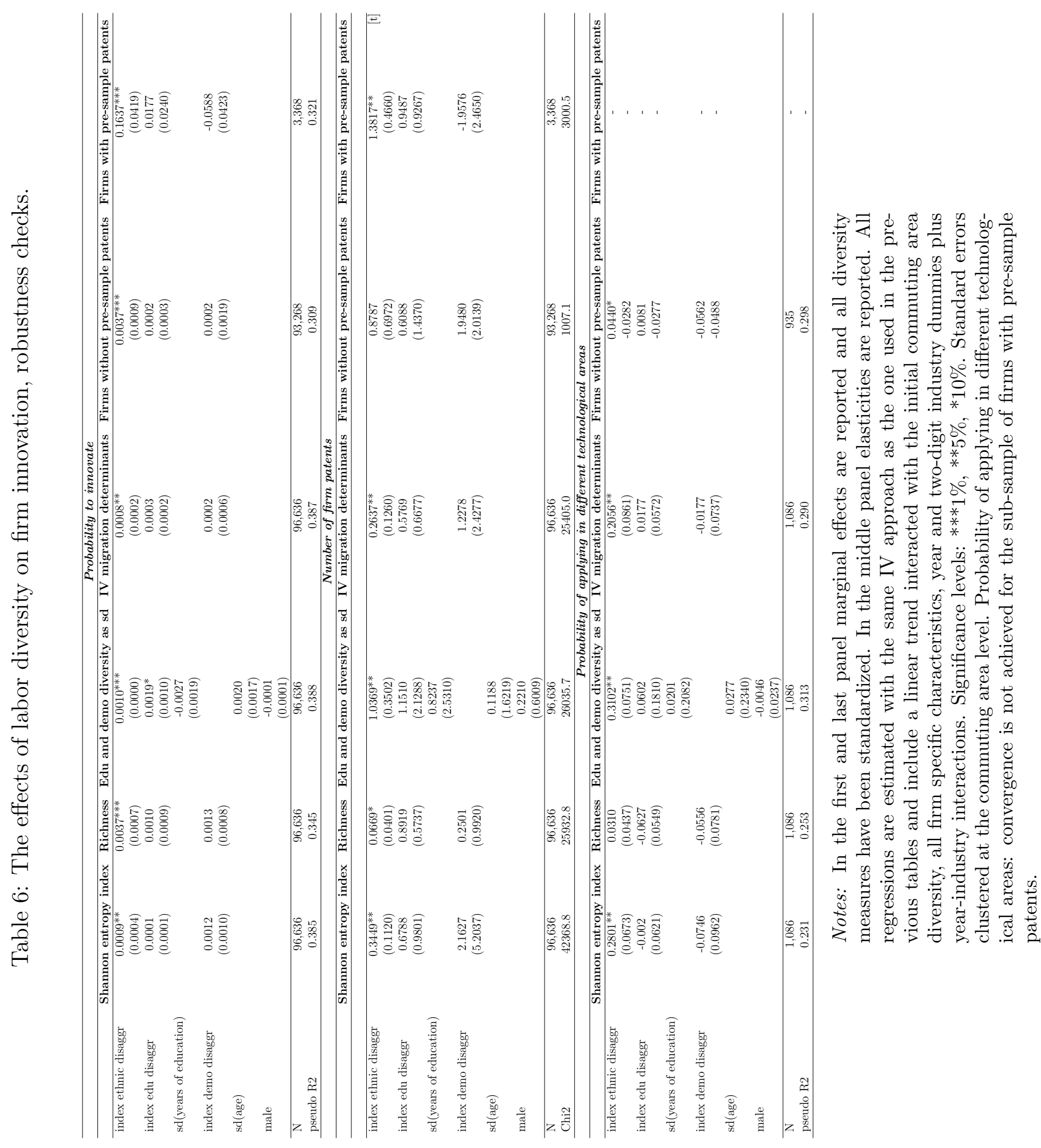




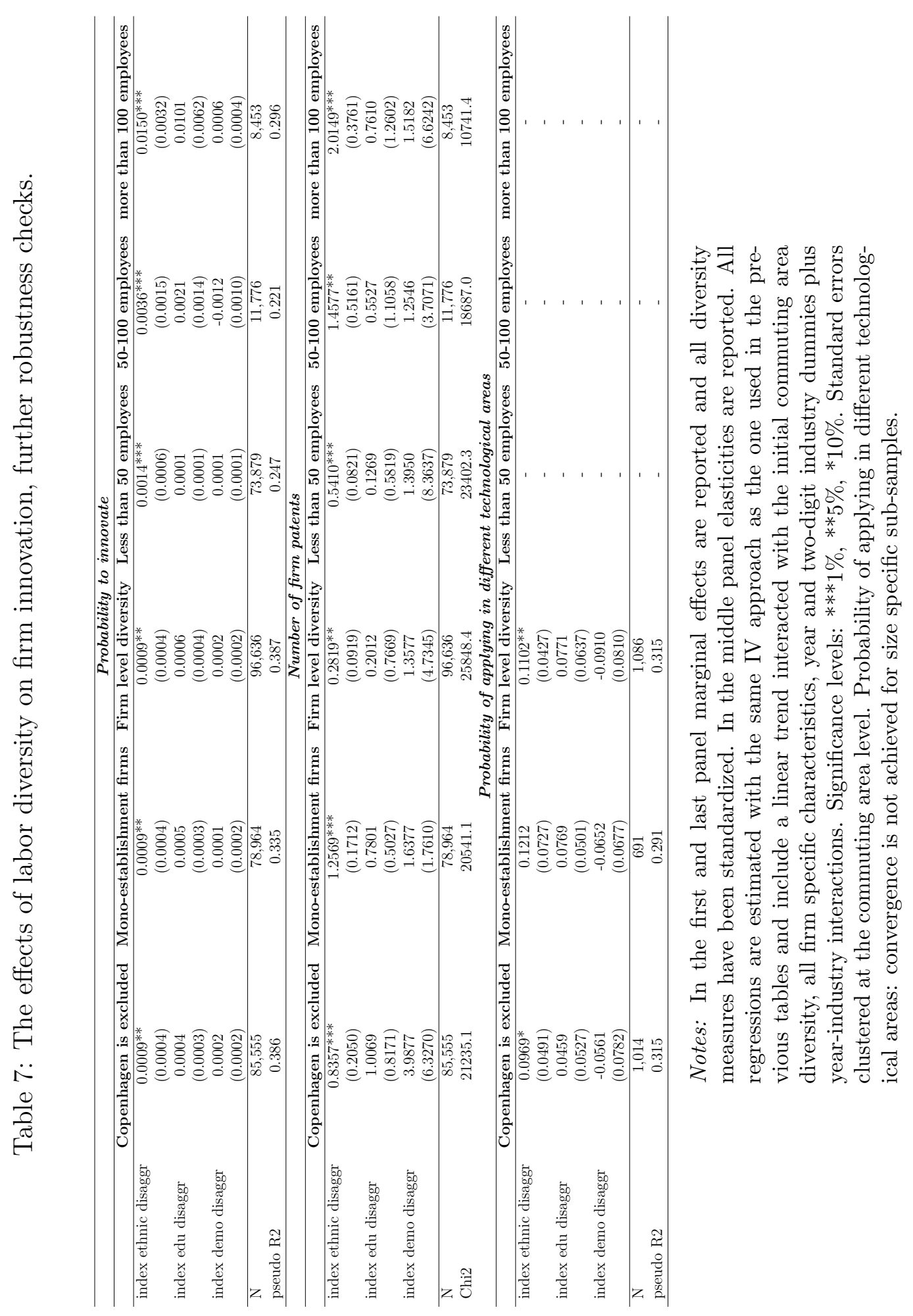




\section{Appendix 1: Groups included in the measure of ethnic diversity}

1) The citizens in the different nationality groups are: Danish: Danish native including second generation immigrants; North America and Oceania: United States, Canada, Australia, New Zealand; Central and South America: Guatemala, Belize, Costa Rica, Honduras, Panama, El Salvador, Nicaragua, Venezuela, Ecuador, Peru, Bolivia, Chile, Argentina, Brazil; Formerly Communist Countries: Armenia, Belarus, Estonia, Georgia, Latvia, Lithuania, Moldova, Russia, Tajikistan, Ukraine, Bulgaria, Czech Republic, Hungary, Poland, Romania, Slovakia, Albania, Bosnia and Herzegovina, Bulgaria, Croatia, Rep. of Macedonia, Montenegro, Serbia, and Slovenia; Muslim Countries: Afghanistan, Algeria, Arab Emirates, Azerbaijan, Bahrain, Bangladesh, Brunei Darussalem, Burkina Faso, Camoros, Chad, Djibouti, Egypt, Eritrea, Gambia, Guinea, Indonesia, Iran, Iraq, Jordan, Kazakstan, Kirgizstan, Kuwait, Lebanon, Libyan Arab Jamahiriya, Malaysia, Maldives, Mali, Mauritania, Morocco, Nigeria, Oman, Pakistan, Palestine, Qatar, Saudi Arabia, Senegal, Sierra Leone, Somalia, Sudan, Syria, Tadzhikstan, Tunisia, Turkey, Turkmenistan, Uzbekistan, Yemen; East Asia: China, Hong Kong, Japan, Korea, Korea Dem. People's Rep. Of, Macao, Mongolia, Taiwan; Asia: all the other Asian countries non included in both East Asia and Muslim Countries categories; Africa: all the other African countries not included in the Muslim Country; Western and Southern Europe: all the other European countries not included in the Formerly Communist Countries category.

2) Using linguistic grouping: Germanic West (Antigua Barbuda, Aruba, Australia, Austria, Bahamas, Barbados, Belgium, Belize, Bermuda, Botswana, Brunei, Cameroon, Canada, Cook Islands, Dominica, Eritrea, Gambia, Germany, Ghana, Grenada, Guyana, Haiti, Ireland, Jamaica, Liberia, Liechtenstein, Luxemburg, Mauritius, Namibia, Netherlands, Netherlands Antilles, New Zealand, Saint Kitts and Nevis, Saint Lucia, Saint Vincent and Grenadines, Seychelles, Sierra Leone, Solomon Islands, South Africa, St. Helena, Suriname, Switzerland, Trinidad and Tobago, Uganda, United Kingdom, United States, Zambia, Zimbabwe), Germanic Nord (Denmark, Iceland, Norway, Sweden), Slavic West (Czech Republic, Poland, Slovakia), Slavic South (Bosnia and Herzegovina, Croatia, Serbia, Slovenia), Slavic East (Belarus, Georgia, Mongolia, Russian Federation, Ukraine), Baltic East (Latvia, Lithuania), Finno-Permic (Finland, Estonia), Ugric (Hungary), Romance (Andorra, Angola, Argentina, Benin, Bolivia, Brazil, Burkina Faso, Cape Verde, Chile, Columbia, Costa Rica, Cote D'Ivoire, Cuba, Djibouti, Dominican Republic, Ecuador, El Salvador, Equatorial Guinea, France, French Guina, Gabon, Guadeloupe, Guatemala, Guinea, Guinea Bissau, Holy See, Honduras, Italy, Macau, Martinique, Mexico, Moldova, Mozambique, Nicaragua, Panama, Peru, Portugal, Puerto Rico, Reunion, Romania, San Marino, Sao Tome, Senegal, Spain, Uruguay, Venezuela), Attic (Cyprus, Greece), Turkic South (Azerbaijan, Turkey, Turkmenistan), Turkic West (Kazakhstan, Kyrgystan), Turkic East (Uzbekistan), Gheg (Albania, Kosovo, Republic of Macedonia, Montenegro), Semitic Central (Algeria, Bahrain, Comoros, Chad, Egypt, Irak, Israel, Jordan, Kuwait, Lebanon, Lybian Arab Jamahiria, Malta, Mauritiania, Morocco, Oman, Qatar, Saudi Arabia, Sudan, Syrian Arab Republic, Tunisia, Yemen, United Arabs Emirates), Indo-Aryan (Bangladesh, 
Fiji, India, Maldives, Nepal, Pakistan, Sri Lanka), Mon-Khmer East (Cambodia), Semitic South (Ethiopia), Malayo-Polynesian West (Indonesia, Philippines), MalayoPolynesian Central East (Kiribati, Marshall Islands, Nauru, Samoa, Tonga), Iranian (Afghanistan, Iran, Tajikistan), Betai (Laos, Thailand), Malayic (Malasya), Cushitic East (Somalia), Viet-Muong (Vietnam), Volta-Congo (Burundi, Congo, Kenya, Lesotho, Malawi, Nigeria, Rwanda, Swaziland, Tanzania, Togo), Barito (Madagascar), Mande West (Mali), Lolo-Burmese (Burma), Chadic West (Niger), Guarani (Paraguay), Himalayish (Buthan), Armenian (Armenia), Sino Tibetan (China, Hong Kong, Singapore, Taiwan), Japonic (Japan, Republic of Korea, Korea D.P.R.O.). 


\section{Appendix 2: External knowledge indexes}

The main literature on agglomeration economies emphasizes the importance of firm's local environment, which may reflect information advantages, labor or other inputs pooling and further beneficial network effects aimed at alleviating the burden represented by fixed costs. A seminal contribution in this field is due to Audretsch and Feldman (1996), who find that industries characterized by elevated R\&D intensity or particularly skilled labor forces present a greater degree of geographic concentration of production. Other relevant studies like Wallsten (2001) and Adams and Jaffe (1996) provide evidence of the geographic extent of knowledge spillovers by computing the distance in miles between each firm-pair. However, the geography is not the only dimension of the external knowledge. In fact, there exists at least another approach which focuses on the concept of technological proximity (Jaffe 1986, Adams 1990). Specifically, the idea that the technology developed by a firm can affect other firms, even though they are not geographically close or no transactions of goods occur between them, has led to the definition of technological proximity as closeness between firm-pairs' technological profiles.

Following both the cited approaches, we construct two indexes of knowledge spillovers. These are weighted sums of firms' codified knowledge proxied by the discounted stock of patent applications. The weighting function for the first index refers to the geographical distance between pairs of workplaces' municipalities and is computed by using the firms' latitude and longitude coordinates (the address of their headquarters). Specifically, assuming a spherical earth of actual earth volume, this method allows us to measure the distance in kilometers between any pair of firms $\mathrm{i}$ and $\mathrm{j} .{ }^{1}$ The first knowledge spillover index is then computed as follows:

$$
K_{-} g o_{i t}=\frac{1}{e^{\text {dist }_{i j}}} \sum_{j \neq i}^{I} \text { disc_stock }_{j t} \text {. }
$$

The second index is instead based on the technological proximity. Following Adams (1990), we use the shares of differently skilled workers to define our alternative weighting function $\psi_{i j}$ that is the uncentered correlation:

$$
\psi_{i j}=\frac{f_{i} f_{j}^{\prime}}{\left[\left(f_{i} f_{i}^{\prime}\right)\left(f_{j} f_{j}^{\prime}\right)\right]^{1 / 2}} .
$$

The components of the generator vector f reflects firm's workforce composition in terms of skills using the disaggregated categorization as described in section 3.1. The second measure of knowledge spillover pool is therefore defined as

\footnotetext{
${ }^{1}$ We use the following formula $d_{i j}=6378.7 * \operatorname{acos}\left\{\sin \left(l_{a t} / 57.2958\right) * \sin \left(l t_{j} / 57.2958\right)+\right.$ $+\cos \left(\right.$ lat $\left._{i} / 57.2958\right) * \cos \left(\right.$ lat $\left._{j} / 57.2958\right) * \cos \left(\operatorname{lon}_{j} / 57.2958-\right.$ lon $\left._{i} / 57.2958\right)$.
} 


$$
K_{-} t_{e c h} h_{i t}=\psi_{i j} \sum_{j \neq i}^{I} d i s c \_s t o c k_{j t} .
$$

Thus, both $K_{-} g e o_{i t}$ and $K_{-} t_{e c h}$ contain weighting functions that might capture the so-called firm's absorptive capacity, which is the ability to identify and exploit the knowledge externally produced (Cohen and Levinthal 1990). 


\section{Appendix 3: Additional results}

Table A1: SUR estimates of the IV first step for the probability to innovate

\begin{tabular}{|c|c|c|c|c|c|c|}
\hline & \multicolumn{3}{|c|}{ Aggregate } & \multicolumn{3}{|c|}{ Disaggregate } \\
\hline & Index ethnic & Index edu & Index demo & Index ethnic & Index edu & Index demo \\
\hline index ethnic com & $\begin{array}{c}0.2712^{* * *} \\
(0.0068)\end{array}$ & $\begin{array}{c}-0.0884^{* * *} \\
(0.0040)\end{array}$ & $\begin{array}{c}-0.0339^{* * *} \\
(0.0024)\end{array}$ & $\begin{array}{c}0.2623^{* * *} \\
(0.0064)\end{array}$ & $\begin{array}{c}-0.0096^{* *} \\
(0.0029)\end{array}$ & $\begin{array}{c}-0.0204^{* * *} \\
(0.0019)\end{array}$ \\
\hline index edu com & $\begin{array}{c}-0.0927^{* * *} \\
(0.0127)\end{array}$ & $\begin{array}{c}0.8169^{* * *} \\
(0.0075)\end{array}$ & $\begin{array}{c}-0.0491^{* * *} \\
(0.0046)\end{array}$ & $\begin{array}{c}-0.1429^{* * *} \\
(0.0132)\end{array}$ & $\begin{array}{c}0.5207^{* * * *} \\
(0.0060)\end{array}$ & $\begin{array}{c}-0.0736^{* * *} \\
(0.0039)\end{array}$ \\
\hline index demo com & $\begin{array}{c}-0.0583^{* *} \\
(0.0194)\end{array}$ & $\begin{array}{c}-0.0331^{* *} \\
(0.0114)\end{array}$ & $\begin{array}{c}0.6209^{* * *} \\
(0.0070)\end{array}$ & $\begin{array}{c}-0.0464^{* *} \\
(0.0223)\end{array}$ & $\begin{array}{c}-0.0272^{* *} \\
(0.0102)\end{array}$ & $\begin{array}{c}0.5926^{* * *} \\
(0.0066)\end{array}$ \\
\hline index ethnic $1990^{*}$ linear trend & $\begin{array}{c}0.0104^{* * *} \\
(0.0010)\end{array}$ & $\begin{array}{c}-0.0055^{* * *} \\
(0.0006)\end{array}$ & $\begin{array}{l}-0.0007^{*} \\
(0.0004)\end{array}$ & $\begin{array}{l}0.0099^{*} \\
(0.0060)\end{array}$ & $\begin{array}{c}0.0060^{* *} \\
(0.0027)\end{array}$ & $\begin{array}{c}0.0009 \\
(0.0018)\end{array}$ \\
\hline index edu $1990 *$ linear trend & $\begin{array}{c}0.0488^{* * * *} \\
(0.0145)\end{array}$ & $\begin{array}{c}0.0889^{* * * *} \\
(0.0085)\end{array}$ & $\begin{array}{c}-0.0321^{* * * *} \\
(0.0052)\end{array}$ & $\begin{array}{c}0.0395^{* * * *} \\
(0.0054)\end{array}$ & $\begin{array}{c}0.0057^{* *} \\
(0.0025)\end{array}$ & $\begin{array}{c}-0.0036^{* *} \\
(0.0016)\end{array}$ \\
\hline index demo $1990^{*}$ linear trend & $\begin{array}{c}0.1068 \\
(0.1451)\end{array}$ & $\begin{array}{c}0.0611 \\
(0.0854)\end{array}$ & $\begin{array}{c}0.1936^{* * *} \\
(0.0521)\end{array}$ & $\begin{array}{c}-0.1670^{* * *} \\
(0.0199)\end{array}$ & $\begin{array}{c}-0.0316^{* * * *} \\
(0.0091)\end{array}$ & $\begin{array}{c}0.0158^{* *} \\
(0.0059)\end{array}$ \\
\hline $\log (\mathrm{K})$ & $\begin{array}{l}0.0012^{*} \\
(0.0007)\end{array}$ & $\begin{array}{c}0.0037^{* * * *} \\
(0.0004)\end{array}$ & $\begin{array}{c}0.0019^{* * *} \\
(0.0002)\end{array}$ & $\begin{array}{c}-0.0015^{*} \\
(0.0008)\end{array}$ & $\begin{array}{c}0.0062^{* * *} \\
(0.0004)\end{array}$ & $\begin{array}{c}0.0014^{* * *} \\
(0.0002)\end{array}$ \\
\hline $\log (\mathrm{L})$ & $\begin{array}{c}0.0793^{* * *} \\
(0.0015)\end{array}$ & $\begin{array}{c}0.0193^{* * * *} \\
(0.0009)\end{array}$ & $\begin{array}{c}0.0216^{* * * *} \\
(0.0005)\end{array}$ & $\begin{array}{c}0.1160 * * * \\
(0.0017)\end{array}$ & $\begin{array}{c}0.0073^{* * *} \\
(0.0008)\end{array}$ & $\begin{array}{c}0.0254^{* * * *} \\
(0.0005)\end{array}$ \\
\hline age1 & $\begin{array}{l}-0.0021 \\
(0.0051)\end{array}$ & $\begin{array}{c}0.0645^{* * * *} \\
(0.0030)\end{array}$ & $\begin{array}{c}-0.0966^{* * *} \\
(0.0018)\end{array}$ & $\begin{array}{c}0.0050 \\
(0.0061)\end{array}$ & $\begin{array}{c}0.1141^{* * *} \\
(0.0028)\end{array}$ & $\begin{array}{c}-0.1041^{* * *} \\
(0.0018)\end{array}$ \\
\hline age2 & $\begin{array}{c}-0.0273^{* * * *} \\
(0.0053)\end{array}$ & $\begin{array}{c}-0.0136^{* * *} \\
(0.0031)\end{array}$ & $\begin{array}{c}-0.0451^{* * * *} \\
(0.0019)\end{array}$ & $\begin{array}{c}-0.0158^{* *} \\
(0.0065)\end{array}$ & $\begin{array}{c}0.0558^{* * *} \\
(0.0030)\end{array}$ & $\begin{array}{c}-0.0242^{* * * *} \\
(0.0019)\end{array}$ \\
\hline age3 & $\begin{array}{c}-0.0187^{* *} \\
(0.0065)\end{array}$ & $\begin{array}{c}0.0137^{* * * *} \\
(0.0038)\end{array}$ & $\begin{array}{c}0.0287^{* * * *} \\
(0.0023)\end{array}$ & $\begin{array}{l}-0.0065 \\
(0.0078)\end{array}$ & $\begin{array}{c}0.0259^{* * *} \\
(0.0036)\end{array}$ & $\begin{array}{c}0.0380^{* * *} \\
(0.0023)\end{array}$ \\
\hline males & $\begin{array}{c}-0.0361^{* * * *} \\
(0.0033)\end{array}$ & $\begin{array}{c}-0.0342^{* * * *} \\
(0.0019)\end{array}$ & $\begin{array}{c}-0.0822^{* * * *} \\
(0.0012)\end{array}$ & $\begin{array}{c}-0.0377^{* * * *} \\
(0.0039)\end{array}$ & $\begin{array}{c}-0.0415^{* * *} \\
(0.0018)\end{array}$ & $\begin{array}{c}-0.0784^{* * *} \\
(0.0012)\end{array}$ \\
\hline $\exp$ & $\begin{array}{c}0.0026^{* *} \\
(0.0013)\end{array}$ & $\begin{array}{c}0.0044^{* * *} \\
(0.0007)\end{array}$ & $\begin{array}{c}0.0067^{* * *} \\
(0.0004)\end{array}$ & $\begin{array}{c}0.0051^{* * *} \\
(0.0015)\end{array}$ & $\begin{array}{c}0.0125^{* * *} \\
(0.0007)\end{array}$ & $\begin{array}{c}0.0066^{* * *} \\
(0.0004)\end{array}$ \\
\hline skill1 & $\begin{array}{c}-0.0001^{* *} \\
(0.0000)\end{array}$ & $\begin{array}{c}0.0008^{* * *} \\
(0.0000)\end{array}$ & $\begin{array}{l}-0.0000 \\
(0.0000)\end{array}$ & $\begin{array}{c}-0.0228^{* * *} \\
(0.0050)\end{array}$ & $\begin{array}{c}-0.0808^{* * *} \\
(0.0023)\end{array}$ & $\begin{array}{c}0.0095^{* * *} \\
(0.0015)\end{array}$ \\
\hline skill2 & $\begin{array}{c}0.0002^{* * *} \\
(0.0000)\end{array}$ & $\begin{array}{c}-0.0006^{* * *} \\
(0.0000)\end{array}$ & $\begin{array}{c}-0.0000^{* * *} \\
(0.0000)\end{array}$ & $\begin{array}{c}0.1265^{* * *} \\
(0.0111)\end{array}$ & $\begin{array}{c}0.4702^{* * *} \\
(0.0051)\end{array}$ & $\begin{array}{c}0.0173^{* * *} \\
(0.0033)\end{array}$ \\
\hline tenure & $\begin{array}{c}-0.0026^{* * *} \\
(0.0003)\end{array}$ & $\begin{array}{c}0.0001 \\
(0.0002)\end{array}$ & $\begin{array}{c}0.0016^{* * *} \\
(0.0001)\end{array}$ & $\begin{array}{c}-0.0033^{* * *} \\
(0.0004)\end{array}$ & $\begin{array}{c}-0.0016^{* * *} \\
(0.0002)\end{array}$ & $\begin{array}{c}0.0016^{* * *} \\
(0.0001)\end{array}$ \\
\hline multi & $\begin{array}{c}-0.0730^{* * *} \\
(0.0021)\end{array}$ & $\begin{array}{c}-0.0210^{* * *} \\
(0.0013)\end{array}$ & $\begin{array}{c}-0.0271^{* * *} \\
(0.0008)\end{array}$ & $\begin{array}{c}-0.1452^{* * *} \\
(0.0025)\end{array}$ & $\begin{array}{c}-0.0248^{* * *} \\
(0.0011)\end{array}$ & $\begin{array}{c}-0.0291^{* * *} \\
(0.0007)\end{array}$ \\
\hline geo_spillover & $\begin{array}{c}0.0001^{* * *} \\
(0.000)\end{array}$ & $\begin{array}{c}0.0001^{* * *} \\
(0.0000)\end{array}$ & $\begin{array}{c}0.0001^{* * *} \\
(0.0000)\end{array}$ & $\begin{array}{c}0.0001^{* * * *} \\
(0.0000)\end{array}$ & $\begin{array}{c}0.0004^{* * *} \\
(0.0000)\end{array}$ & $\begin{array}{c}0.0001^{* * *} \\
(0.0000)\end{array}$ \\
\hline tech_spillover & $\begin{array}{c}0.0001^{* * *} \\
(0.000)\end{array}$ & $\begin{array}{c}0.0001^{* * *} \\
(0.0000)\end{array}$ & $\begin{array}{c}0.0001^{* * *} \\
(0.0000)\end{array}$ & $\begin{array}{c}0.0001^{* * *} \\
(0.0000)\end{array}$ & $\begin{array}{c}0.0000^{* * *} \\
(0.0000)\end{array}$ & $\begin{array}{c}0.0001^{* * *} \\
(0.0000)\end{array}$ \\
\hline size/industry/year/industry*year dummies & yes & yes & yes & yes & yes & yes \\
\hline shares of foreigners by group of countries & yes & yes & yes & yes & yes & yes \\
\hline shares of employees by occupation & yes & yes & yes & yes & yes & yes \\
\hline F test (excluded instruments); p-value & & $185.81 ; 0.000$ & & & $165.79 ; 0.000$ & \\
\hline $\begin{array}{l}\mathrm{N} \\
\mathrm{R} 2\end{array}$ & & $\begin{array}{c}96,636 \\
0.509\end{array}$ & & & $\begin{array}{c}96,636 \\
0.555\end{array}$ & \\
\hline
\end{tabular}

Notes: The dependent variables are all diversity indexes. Significance levels: ${ }^{* * *} 1 \%$, $* * 5 \%,{ }^{*} 10 \%$. Standard errors clustered at the commuting area level. 
Table A2: estimates of the IV first step for the number of patent applications

\begin{tabular}{|c|c|c|c|c|c|c|}
\hline & \multicolumn{3}{|c|}{ Aggregate } & \multicolumn{3}{|c|}{ Disaggregate } \\
\hline & Index ethnic & Index edu & Index demo & Index ethnic & Index edu & Index demo \\
\hline index ethnic com & $\begin{array}{c}0.2762^{* * *} \\
(0.0073)\end{array}$ & $\begin{array}{c}-0.0192^{* * *} \\
(0.0030)\end{array}$ & $\begin{array}{c}-0.0346^{* * *} \\
(0.0022)\end{array}$ & $\begin{array}{c}0.2519^{* * *} \\
(0.0062)\end{array}$ & $\begin{array}{c}-0.0067^{* *} \\
(0.0032)\end{array}$ & $\begin{array}{c}-0.0177^{* * *} \\
(0.0036)\end{array}$ \\
\hline index edu com & $\begin{array}{c}-0.1446^{* * *} \\
(0.0130)\end{array}$ & $\begin{array}{c}0.2608^{* * *} * \\
(0.0063)\end{array}$ & $\begin{array}{c}-0.0468^{* * * *} \\
(0.0053)\end{array}$ & $\begin{array}{c}-0.1303^{* * *} * \\
(0.0122)\end{array}$ & $\begin{array}{c}0.5346^{* * * *} \\
(0.0062)\end{array}$ & $\begin{array}{c}-0.0162^{* * *} \\
(0.0036)\end{array}$ \\
\hline index demo com & $\begin{array}{l}-0.0221 \\
(0.0188)\end{array}$ & $\begin{array}{c}0.0956^{* * *} \\
(0.0082)\end{array}$ & $\begin{array}{c}0.6177^{* * * *} \\
(0.0073)\end{array}$ & $\begin{array}{c}-0.0489^{* *} \\
(0.0213)\end{array}$ & $\begin{array}{c}-0.0355^{* * *} \\
(0.0102)\end{array}$ & $\begin{array}{c}0.0729^{* * * *} \\
(0.0062)\end{array}$ \\
\hline index ethnic $1990^{*}$ linear trend & $\begin{array}{c}0.0103^{* * * *} \\
(0.0008)\end{array}$ & $\begin{array}{l}-0.0046 \\
(0.0012)\end{array}$ & $\begin{array}{l}-0.0012^{*} \\
(0.0000)\end{array}$ & $\begin{array}{l}0.0102^{*} \\
(0.0056)\end{array}$ & $\begin{array}{c}0.0056^{* *} \\
(0.0027)\end{array}$ & $\begin{array}{c}0.0010 \\
(0.0022)\end{array}$ \\
\hline index edu $1990^{*}$ linear trend & $\begin{array}{c}0.0493^{* * *} \\
(0.014)\end{array}$ & $\begin{array}{c}0.0893^{* * * *} \\
(0.0088)\end{array}$ & $\begin{array}{c}-0.0319^{* * * *} \\
(0.0053)\end{array}$ & $\begin{array}{c}0.0389^{* * * *} \\
(0.0046)\end{array}$ & $\begin{array}{c}0.0057^{* *} \\
(0.0022)\end{array}$ & $\begin{array}{c}-0.0036^{* *} \\
(0.0016)\end{array}$ \\
\hline index demo $1990 *$ linear trend & $\begin{array}{c}0.1068 \\
(0.1453)\end{array}$ & $\begin{array}{c}0.0608 \\
(0.0852)\end{array}$ & $\begin{array}{c}0.1937^{* * *} \\
(0.0524)\end{array}$ & $\begin{array}{c}-0.1666^{* * *} \\
(0.0202)\end{array}$ & $\begin{array}{c}-0.0319^{* * * *} \\
(0.0088)\end{array}$ & $\begin{array}{c}0.0160^{* *} \\
(0.0056)\end{array}$ \\
\hline $\log (\mathrm{K})$ & $\begin{array}{c}0.0008 \\
(0.0007)\end{array}$ & $\begin{array}{c}0.0035^{* * *} \\
(0.0004)\end{array}$ & $\begin{array}{c}0.0020^{* * *} \\
(0.0002)\end{array}$ & $\begin{array}{c}-0.0021^{* *} \\
(0.0008)\end{array}$ & $\begin{array}{c}0.0061^{* * *} \\
(0.0004)\end{array}$ & $\begin{array}{c}0.0016^{* * * *} \\
(0.0002)\end{array}$ \\
\hline $\log (\mathrm{L})$ & $\begin{array}{c}0.0789^{* * *} \\
(0.0015)\end{array}$ & $\begin{array}{c}0.0189^{* * *} \\
(0.0009)\end{array}$ & $\begin{array}{c}0.0218^{* * *} \\
(0.0005)\end{array}$ & $\begin{array}{c}0.1151^{* * *} \\
(0.0017)\end{array}$ & $\begin{array}{c}0.0075^{* * *} \\
(0.0008)\end{array}$ & $\begin{array}{c}0.0258^{* * *} * \\
(0.0005)\end{array}$ \\
\hline discounted stock of applications & $\begin{array}{c}-0.0007^{* *} \\
(0.0003)\end{array}$ & $\begin{array}{c}0.0005^{* *} \\
(0.0002)\end{array}$ & $\begin{array}{l}-0.0001 \\
(0.0001)\end{array}$ & $\begin{array}{c}-0.0015^{* * *} \\
(0.0004)\end{array}$ & $\begin{array}{c}-0.0006^{* * * *} \\
(0.0002)\end{array}$ & $\begin{array}{c}-0.0002^{*} \\
(0.0001)\end{array}$ \\
\hline $\log$ (fixed effects) & $\begin{array}{c}0.0112 \\
(0.0140)\end{array}$ & $\begin{array}{c}0.0297^{* * *} \\
(0.0082)\end{array}$ & $\begin{array}{c}-0.0130^{* *} \\
(0.0050)\end{array}$ & $\begin{array}{c}0.0684^{* * *} \\
(0.0166)\end{array}$ & $\begin{array}{l}-0.0148^{*} \\
(0.0076)\end{array}$ & $\begin{array}{c}-0.0162^{* *} \\
(0.0050)\end{array}$ \\
\hline fixed effect dummy & $\begin{array}{c}0.0284^{* * *} * \\
(0.0036)\end{array}$ & $\begin{array}{c}0.0006 \\
(0.0021)\end{array}$ & $\begin{array}{c}0.0009 \\
(0.0013)\end{array}$ & $\begin{array}{c}0.0227^{* * * *} \\
(0.0043)\end{array}$ & $\begin{array}{c}0.0125^{* * * *} \\
(0.0019)\end{array}$ & $\begin{array}{l}-0.0002 \\
(0.0013)\end{array}$ \\
\hline age1 & $\begin{array}{l}-0.0016 \\
(0.0051)\end{array}$ & $\begin{array}{c}0.0647^{* * * *} \\
(0.0030)\end{array}$ & $\begin{array}{c}-0.0966^{* * * *} \\
(0.0018)\end{array}$ & $\begin{array}{c}0.0060 \\
(0.0061)\end{array}$ & $\begin{array}{c}0.1141^{* * * *} \\
(0.0028)\end{array}$ & $\begin{array}{c}-0.1043^{* * *} \\
(0.0018)\end{array}$ \\
\hline age2 & $\begin{array}{c}-0.0273^{* * *} \\
(0.0053)\end{array}$ & $\begin{array}{c}-0.0132 * * * \\
(0.0031)\end{array}$ & $\begin{array}{c}-0.0452^{* * * *} \\
(0.0019)\end{array}$ & $\begin{array}{c}-0.0151^{* *} \\
(0.0065)\end{array}$ & $\begin{array}{c}0.0557^{* * * *} \\
(0.0030)\end{array}$ & $\begin{array}{c}-0.0244^{* * *} \\
(0.0019)\end{array}$ \\
\hline age3 & $\begin{array}{c}-0.0189^{* *} \\
(0.0065)\end{array}$ & $\begin{array}{c}0.0137^{* * *} \\
(0.0038)\end{array}$ & $\begin{array}{c}0.0287^{* * * *} \\
(0.0023)\end{array}$ & $\begin{array}{l}-0.0063 \\
(0.0078)\end{array}$ & $\begin{array}{c}0.0257^{* * *} * \\
(0.0036)\end{array}$ & $\begin{array}{c}0.0379 * * * \\
(0.0023)\end{array}$ \\
\hline males & $\begin{array}{c}-0.0353^{* * *} \\
(0.0033)\end{array}$ & $\begin{array}{c}-0.0337^{* * * *} \\
(0.0019)\end{array}$ & $\begin{array}{c}-0.0824^{* * * *} \\
(0.0012)\end{array}$ & $\begin{array}{c}-0.0367^{* * *} \\
(0.0039)\end{array}$ & $\begin{array}{c}-0.0414^{* * *} * \\
(0.0018)\end{array}$ & $\begin{array}{c}-0.0786^{* * * *} \\
(0.0012)\end{array}$ \\
\hline $\exp$ & $\begin{array}{l}0.0023^{*} \\
(0.0013)\end{array}$ & $\begin{array}{c}0.0044^{* * *} \\
(0.0007)\end{array}$ & $\begin{array}{c}0.0067^{* * *} * \\
(0.0004)\end{array}$ & $\begin{array}{c}0.0049^{* *} \\
(0.0015)\end{array}$ & $\begin{array}{c}0.0123^{* * *} \\
(0.0007)\end{array}$ & $\begin{array}{c}0.0066^{* * *} * \\
(0.0004)\end{array}$ \\
\hline skill1 & $\begin{array}{c}-0.0001^{* *} \\
(0.0000)\end{array}$ & $\begin{array}{c}0.0009^{* * *} \\
(0.0000)\end{array}$ & $\begin{array}{l}-0.0000 \\
(0.0000)\end{array}$ & $\begin{array}{c}-0.0229^{* * *} \\
(0.0050)\end{array}$ & $\begin{array}{c}-0.0808^{* * *} \\
(0.0023)\end{array}$ & $\begin{array}{c}0.0096^{* * *} \\
(0.0015)\end{array}$ \\
\hline skill2 & $\begin{array}{c}0.0002^{* * *} \\
(0.0000)\end{array}$ & $\begin{array}{c}-0.0006^{* * * *} \\
(0.0000)\end{array}$ & $\begin{array}{c}-0.0000^{* * * *} \\
(0.0000)\end{array}$ & $\begin{array}{c}0.1240^{* * *} \\
(0.0111)\end{array}$ & $\begin{array}{c}0.4703^{* * *} \\
(0.0051)\end{array}$ & $\begin{array}{c}0.0181^{* * *} * \\
(0.0033)\end{array}$ \\
\hline tenure & $\begin{array}{c}-0.0027^{* * *} * \\
(0.0003)\end{array}$ & $\begin{array}{c}0.0001 \\
(0.0002)\end{array}$ & $\begin{array}{c}0.0016^{* * *} \\
(0.0001)\end{array}$ & $\begin{array}{c}-0.0033^{* * *} * \\
(0.0004)\end{array}$ & $\begin{array}{c}-0.0017^{* * *} * \\
(0.0002)\end{array}$ & $\begin{array}{c}0.0016^{* * *} \\
(0.0001)\end{array}$ \\
\hline multi & $\begin{array}{c}-0.0728^{* * *} \\
(0.0021)\end{array}$ & $\begin{array}{c}-0.0213^{* * *} \\
(0.0013)\end{array}$ & $\begin{array}{c}-0.0270^{* * * *} \\
(0.0008)\end{array}$ & $\begin{array}{c}-0.1446^{* * *} \\
(0.0025)\end{array}$ & $\begin{array}{c}-0.0247^{* * * *} \\
(0.0011)\end{array}$ & $\begin{array}{c}-0.0291^{* * *} \\
(0.0007)\end{array}$ \\
\hline geo_spillover & $\begin{array}{c}0.0001^{* * *} \\
(0.0000)\end{array}$ & $\begin{array}{c}0.0001^{* * *} \\
(0.0000)\end{array}$ & $\begin{array}{c}0.0001^{* * *} \\
(0.0000)\end{array}$ & $\begin{array}{c}0.0001^{* * *} \\
(0.0000)\end{array}$ & $\begin{array}{c}0.0004^{* * *} \\
(0.0000)\end{array}$ & $\begin{array}{c}0.0001^{* * *} \\
(0.0000)\end{array}$ \\
\hline tech_spillover & $\begin{array}{c}0.0001^{* * *} \\
(0.0000)\end{array}$ & $\begin{array}{c}0.0001^{* *} \\
(0.0000)\end{array}$ & $\begin{array}{c}-0.0001^{* * *} \\
(0.0000)\end{array}$ & $\begin{array}{c}0.0001^{* * *} \\
(0.0000)\end{array}$ & $\begin{array}{c}0.0000^{* * *} \\
(0.0000)\end{array}$ & $\begin{array}{c}-0.0001^{* * *} \\
(0.0000)\end{array}$ \\
\hline size/industry/year/industry*year dummies & yes & yes & yes & yes & yes & yes \\
\hline shares of foreigners by group of countries & yes & yes & yes & yes & yes & yes \\
\hline shares of employees by occupation & yes & yes & yes & yes & yes & yes \\
\hline F test (excluded instruments); p-value & & $179.22 ; 0.000$ & & & $163.64 ; 0.000$ & \\
\hline $\begin{array}{l}\mathrm{N} \\
\mathrm{R} 2\end{array}$ & & $\begin{array}{c}96,636 \\
0.509\end{array}$ & & & $\begin{array}{c}96,636 \\
0.552\end{array}$ & \\
\hline
\end{tabular}

Notes: The dependent variables are all diversity indexes. Significance levels: ${ }^{* * *} 1 \%$, ${ }^{*} 5 \%$, $* 10 \%$. Standard errors clustered at the firm level. 


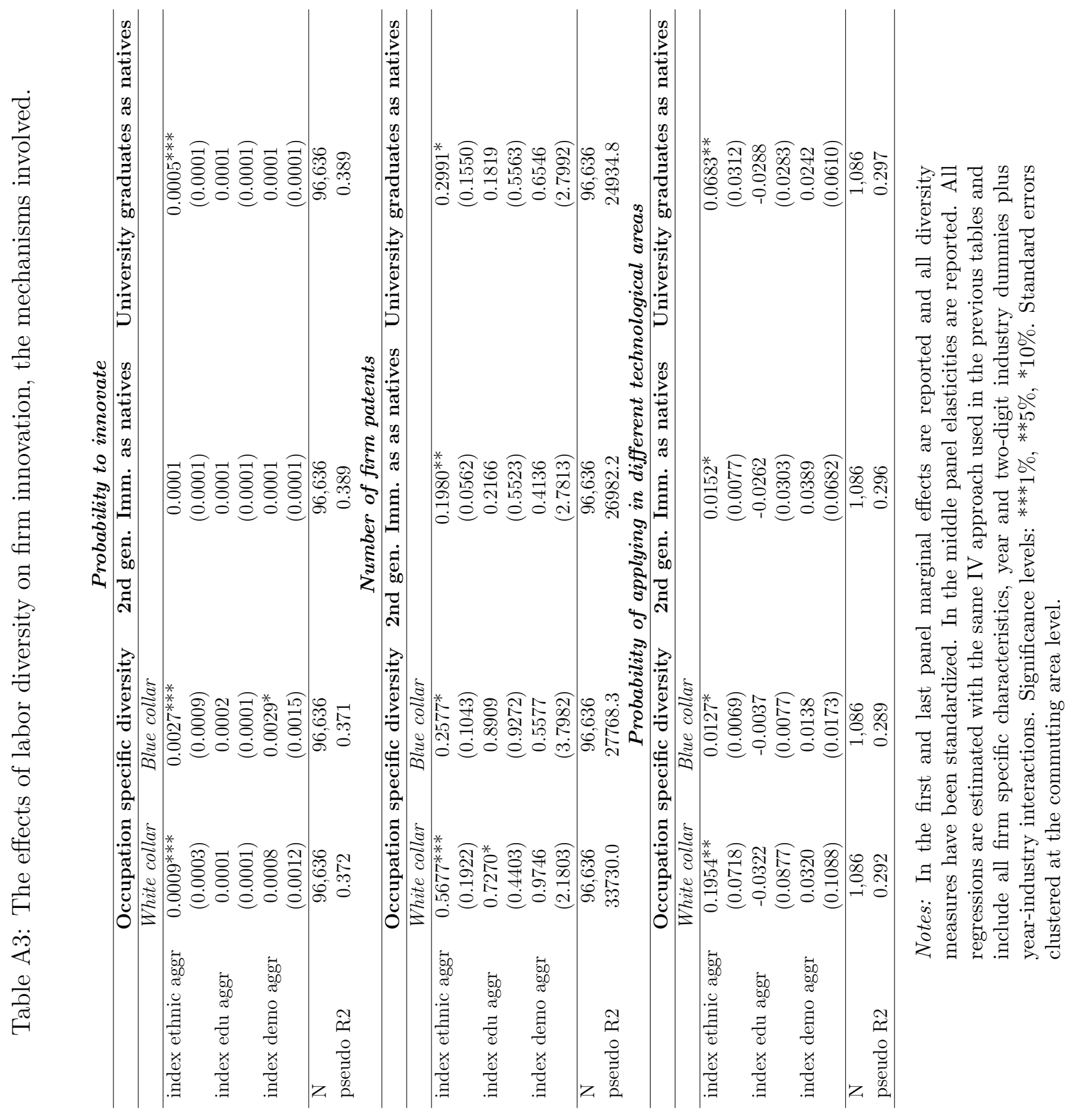




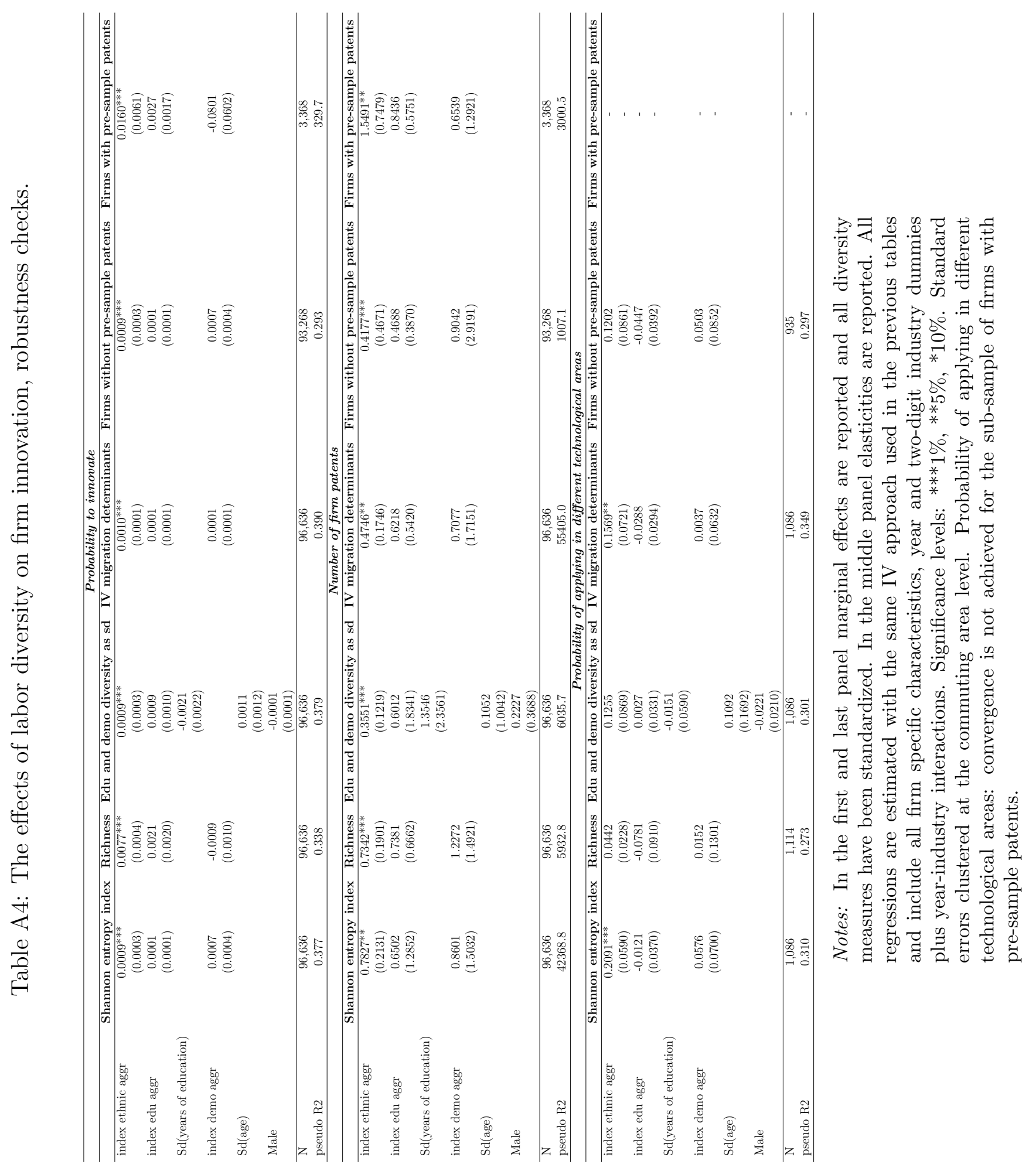




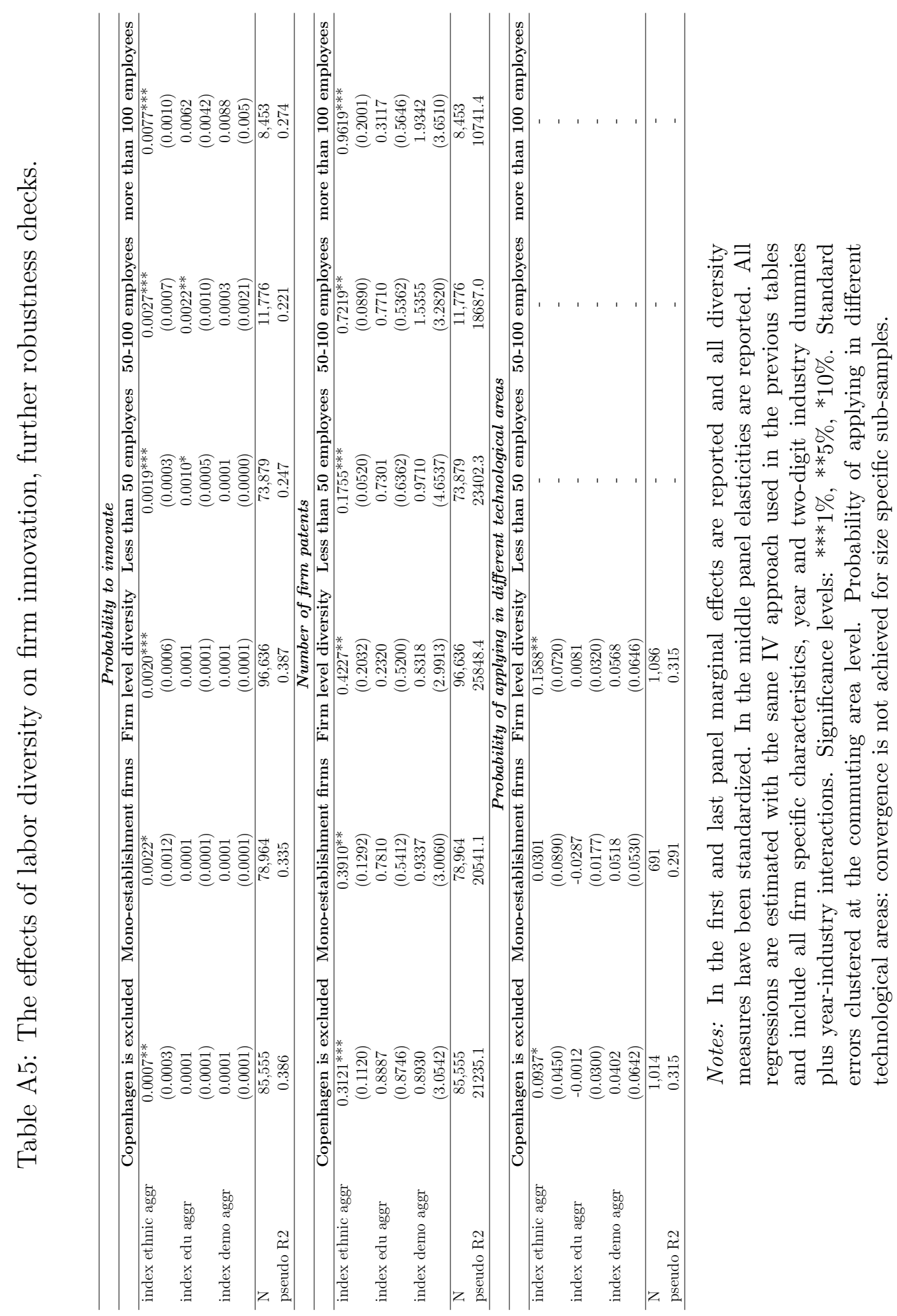

